\title{
REVIEW ARTICLE OPEN Diagnosis and treatment of schizotypal personality disorder: evidence from a systematic review
}

\author{
Sophie K. Kirchner ${ }^{1}$, Astrid Roeh ${ }^{1}$, Jana Nolden ${ }^{1}$ and Alkomiet Hasan ${ }^{1}$
}

The main objective of this review was to evaluate studies on the diagnosis, treatment, and course of schizotypal personality disorder and to provide a clinical guidance on the basis of that evaluation. A systematic search in the PubMed/MEDLINE databases was conducted. Two independent reviewers extracted and assessed the quality of the data. A total of 54 studies were eligible for inclusion: 18 were on diagnostic instruments; 22, on pharmacological treatment; 3 , on psychotherapy; and 13, on the longitudinal course of the disease. We identified several suitable and reliable questionnaires for screening (PDQ-4+ and SPQ) and diagnosing (SIDP, SIDP-R, and SCID-II) schizotypal personality disorder. Second-generation antipsychotics (mainly risperidone) were the most often studied drug class and were described as beneficial. Studies on the longitudinal course described a moderate remission rate and possible conversion rates to other schizophrenia spectrum disorders. Because of the heterogeneity of the studies and the small sample sizes, it is not yet possible to make evidence-based recommendations for treatment. This is a systematic evaluation of diagnostic instruments and treatment studies in schizotypal personality disorder. We conclude that there is currently only limited evidence on which to base treatment decisions in this disorder. Larger interventional trials are needed to provide the data for evidence-based recommendations.

npj Schizophrenia (2018)4:20; doi:10.1038/s41537-018-0062-8

\section{INTRODUCTION}

Schizotypy is a heterogenous syndrome that is expressed across multiple dimensions, including cognitive-perceptual, disorganized, and interpersonal symptoms ${ }^{1}$ or according to the symptomology of schizophrenia, positive, negative, and disorganized factors. ${ }^{2-4}$ Raine ${ }^{1}$ described two types of schizotypy: (1) neurodevelopmental schizotypy with relatively stable traits and significant brain and neurocognitive impairments that predispose to schizophrenia, and (2) pseudoschizotypy, a pronounced psychosocial entity with more symptom fluctuation that is unrelated to schizophrenia. Schizotypy, as a broader collection of both clinical and nonclinical traits, is assessed by psychometric inventories such as the Wisconsin Scales of Schizotypy. ${ }^{3}$ The assessments for schizotypal traits are mainly used to define a high-risk group and its proneness to psychosis. ${ }^{5}$ Mason described 16 different schizotypy scales that were based on clinical concepts or definitions and six scales for psychometric/personality measures of schizotypy. ${ }^{5}$

According to the theoretical models of Meehl, ${ }^{6,7}$ Lenzenweger, ${ }^{8}$ Chapman, ${ }^{9}$ and Kwapil, ${ }^{10}$ schizotypy is a premorbid condition. The term schizotypy refers to both people with schizotypal personality disorder (STPD) and healthy individuals in the general population with certain personality traits and a latent liability for psychosis. ${ }^{1}$ Consequently, research has been performed in both clinical patients and healthy schizotypal individuals. Several authors argue for a dimensional approach and a continuum between schizotypal traits and schizophrenia spectrum disorder ${ }^{1,11,12}$; support for their argument is provided by genetic and linkage studies showing a considerable overlap between genetic association profiles in schizotypy and schizophrenia. ${ }^{13,14}$
Since the introduction of the diagnosis of STPD in Diagnostic and Statistical Manual of Mental Disorders, Third Edition (DSM-III) in 1980, the diagnosis and treatment of STPD have remained difficult because of the lack of evidence-based algorithms. The original STPD item set was derived from the criteria of borderline schizophrenia seen in the relatives of schizophrenia patients. The differentiation between schizotypal traits and STPD is clinically important and reflects the degree of impairment in occupational and interpersonal functioning and the severity of symptom presentation. ${ }^{14}$ This review focuses on the diagnosis of and therapeutic approaches in patients with a disease severity that fulfills the criteria of STPD not only as a premorbid condition or risk state but also as a separate diagnostic entity.

For years, the International Classification of Diseases (ICD) from the World Health Organization (WHO) and other classification instruments, e.g., the DSM from the American Psychiatric Association (APA), have differed in their classification of STPD (referred to as schizotypal disorder in the ICD): In ICD-9 and -10, it is listed under schizophrenia spectrum disorders, whereas in DSM-III to -5 it is classified as a personality disorder. In the forthcoming ICD-11, it will remain in the block of schizophrenia spectrum disorders. $^{15}$ In DSM-5, a diagnosis of STPD is defined by the following symptom categories: (1) general impairments in personality and self-functioning (identity and self-direction) and in interpersonal functioning (empathy, intimacy); (2) STPD-specific pathological personality traits, described as psychoticism, eccentricity, cognitive and perceptual dysregulation, and unusual beliefs and experiences, (3) detachment characterized by restricted affectivity and withdrawal, and (4) negative affectivity characterized by suspiciousness. In ICD-10, ${ }^{16}$ and very likely in ICD-11, however, schizotypal disorder (F21) is characterized by eccentric

\footnotetext{
${ }^{1}$ Department of Psychiatry and Psychotherapy, Ludwig-Maximilians-University, Munich, Germany
}

Correspondence: Sophie K. Kirchner (SophieKathrin.Kirchner@med.uni-muenchen.de)

Received: 5 November 2017 Revised: 15 August 2018 Accepted: 21 August 2018

Published online: 03 October 2018 
behavior and changes in thinking and affect similar to those in schizophrenia; the evolution and course of the disease resemble those of a personality disorder (PD).

The prevalence of STPD has been described as ranging from $0.6 \%$ in a Norwegian sample to $4.6 \%$ in an American sample. ${ }^{17}$ Men (4.2\%) are more often affected than women (3.7\%). ${ }^{17}$ Common differential diagnoses are other PDs such as the borderline personality disorder (BPD), attention-deficit disorder (inattentive type), social anxiety disorder, autism-spectrum disorder, and dysthymia. ${ }^{18}$ Comorbidities can complicate the disease course and treatment responses, and several studies focus on interventions for patients with comorbid obsessive-compulsive disorder $(O C D)^{19}$ and BPD. Schizotypy occurs more often in relatives of patients with schizophrenia or a Cluster A PD. Twin studies showed highly stable genetic factors and rather transient environmental factors for an increased risk for the schizotypal syndrome ${ }^{20}$ and genetic risk variants for schizophrenia could also be linked to STPD. ${ }^{21-23}$ The conversion rates from STPD to schizophrenia spectrum disorders vary between 20 and $>40 \%$, depending on the follow-up interval. ${ }^{1,24}$ Imaging studies detected numerous group-level differences in the size of specific brain regions in individuals with STPD or schizotypy in comparison with healthy participants, patients with schizophrenia, and patients with other PDs. ${ }^{18}$

Despite these research efforts, evidence-based recommendations are still lacking for the diagnosis and treatment of STPD. National and international treatment guidelines for schizophrenia spectrum disorders (e.g., from the APA, the National Institute for Health and Care Excellence and World Federation of Societies of Biological Psychiatry (WFSBP)) do not discuss this topic, and specific guidelines for personality disorders pay only little attention to STPD. ${ }^{25}$ Rosell et al. $^{18}$ recently published a nonsystematic literature review on the epidemiology, functional impairment, heritability and genetics, cognitive impairments, social-affective disturbances, and neurobiology of STPD. This detailed review provides a deeper insight into the pathophysiology of and experimental research on STPD and includes information on imaging and genetic and psychological testing. ${ }^{18}$ Nevertheless, it remains unclear which diagnostic tools, medication, or psychotherapy are recommended. Therefore, the main objective of this systematic review, which was based in principle on the recommendation of the Preferred Reporting Items for Systematic Reviews and Meta-Analyses group, ${ }^{26}$ was to evaluate the literature on the diagnosis and treatment of patients seeking help for STPD. In addition, it offers some information on the longitudinal course of STPD and conversion rates to other schizophrenia spectrum disorders.

\section{RESULTS}

Articles on diagnostic instruments

Study characteristics. When examining the articles on diagnostic instruments, we focused on studies that tested disease criteria ${ }^{27-}$ 31 and clinical diagnostic questionnaires for STPD. ${ }^{32-39}$ One study did not specifically evaluate a diagnostic questionnaire but compared a factor analysis model with established questionnaires. ${ }^{40}$

Individual outcomes. Five studies aimed at evaluating the variables of the diagnostic criteria, the shifts in diagnosis from DSM-III to -5 or ICD-8 to -10 and their effect on diagnostic sensitivity, specificity, and diagnostic overlap, $27,28,30,31,41$ as indicated in Table 1 . The reliability of the DSM-III criteria had an adequate mean kappa of $0.71 .^{27}$ In DSM-III, the diagnoses of BPD and STPD interacted on the symptom level. ${ }^{27}$ In DSM-III-R, the threshold for an STPD diagnosis was raised, and the number of STPD diagnoses consequently decreased by $40 \%$. This offered a sharper discrimination between STPD and related PDs, such as BPD and schizoid PD. ${ }^{30}$ In the evolution of the ICD system, the threshold for meeting symptom criteria was also crucial for differential diagnosis: Whereas in ICD-8/-9 less patients would have been diagnosed with STPD, in ICD-10 the threshold was lowered and more patients were diagnosed with STPD. In the ICD system, the severity of the disease may mark the discrimination between STPD and schizophrenia, which would favor a dimensional diagnosis concept. ${ }^{31}$ Most of the studies evaluated the inter-rater reliability (which ranged from 0.62 to 0.91 ) and test-retest reliabilities (which ranged from 0.64 to 0.84 ) of the diagnostic instruments; reliabilities were adequate (see Table 1). Among the diagnostic instruments, three were identified as being suitable for diagnosis because they had adequate reliabilities and validities for the respective diagnostic criteria: the Structured Interview for DSM-III Personality Disorder (SIDP), ${ }^{33}$ the Semistructured Interview for DSM-III-R Personality Disorders (SIDP-R), ${ }^{35}$ and the Structured Clinical Interview for DSM-IV (SCID-II) ${ }^{37}$ (see Table 1). The self-report instruments Schizotypal Personality Questionnaire (SPQ) and Schizotypal Personality QuestionnaireBrief (SPQ-B) were designed as screening instruments for STPD. The SPQ-B shows adequate internal consistency (coefficient kappa $=0.87),{ }^{42}$ and the SPQ shows strong correlations between patients' responses and SCID-II-rated symptoms. ${ }^{38,43}$ The Personality Diagnostic Questionnaire-4+ (PDQ-4+) is also a self-report instrument for diagnosing PD. It has more false-positive results than the SCID-II and is therefore only useful as a screening tool for PDs but not as a diagnostic tool. ${ }^{44}$ The Minnesota Multiphasic Personality Inventory (MMPI) could not differentiate between individuals with STPD and schizophrenia. ${ }^{45}$ However, a distinct profile (MMPI 2-7-8) showed an enrichment of diagnoses of Cluster A PDs when compared with SIDP-IV interviews. None of the instruments was designed to evaluate disease severity. Three studies compared diagnostic interviews with factor analysis models. ${ }^{35,40,44}$ According to Battaglia et al. $^{35}$, the three factors cognitive-perceptual, interpersonal, and oddness best describe the diagnosis of STPD; Fossati et al. ${ }^{37}$ made the same statement, but these two studies had overlapping patient cohorts. Sanislow et al. $^{40}$ developed a four-factor model and argued that it was significantly better than the established unitary "generic" model. ${ }^{40}$ Please see Table 1 for details.

\section{Articles on interventional drug treatment trials}

Study characteristics. Most of the studies were prospective double-blind, placebo-controlled trials, ${ }^{46-56}$ and all publications reported single-center results. We also identified one doubleblind, treatment-controlled trial; ${ }^{57}$ one single-blind, placebocontrolled trial; ${ }^{58}$ four open-label trials; ${ }^{59-62}$ one retrospective study ${ }_{i}^{63}$ and four case reports. ${ }^{64-67}$ Please see Table $2 A, B$ and Supplementary Table 3 and 4 for further study details and level of evidence (LoE) grading. In total, 16 individual drug treatments were studied. The most frequently studied drug was risperidone, ${ }^{50,53,54,62}$ and the most frequently studied class of drugs were the antipsychotics, $47,48,50,53,54,57-60,62,63,66$ followed by the antidepressants. ${ }^{46,61,64,65}$ Six studies tested other neuroactive drugs. ${ }^{49,51,52,55,56,67}$ In most studies, the main outcome measurement was a general psychiatric symptom scale, such as the Brief Psychiatric Rating Scale, ${ }^{60,63,67}$ the Hopkins Symptom Checklist, ${ }^{48,61}$ and the Psychiatric Assessment Interview. ${ }^{57}$ Three trials used interviews for specific psychotic symptoms, such as the Positive and Negative Symptom Scale (PANSS). ${ }^{50,53,56}$ Some studies focused on patients with comorbidities of OCD or BPD and consequently measured outcome with the Yale-Brown Obsessive Compulsive Scale (YBOCS) ${ }^{46,48,59,66}$ or the SelfInjurious Behavior scale. ${ }^{47}$ One study used a specific tool, the $S P Q$, to assess the severity of STPD as an additional outcome measurement tool. ${ }^{50}$ Common secondary outcome tools were 


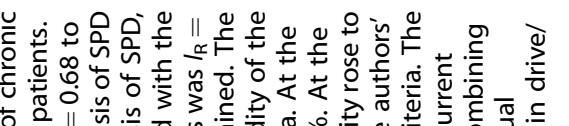

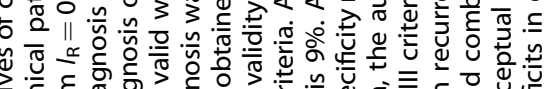

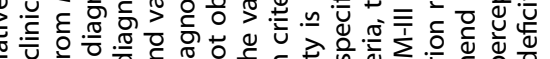

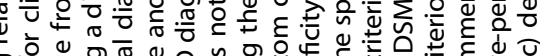

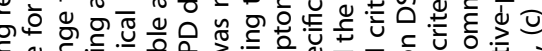

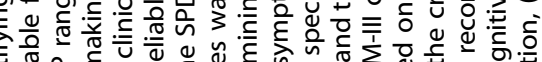

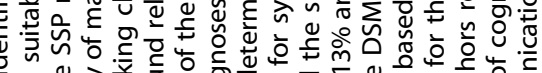

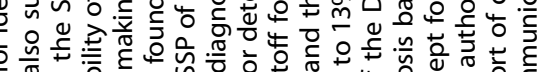

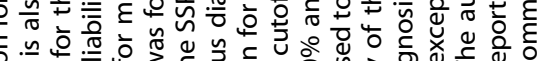

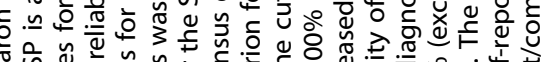

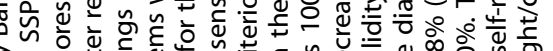

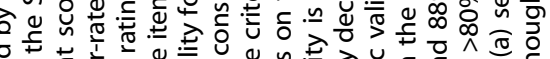

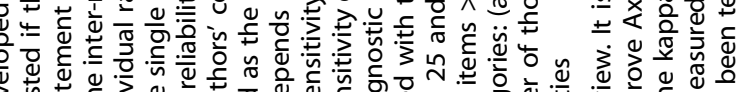

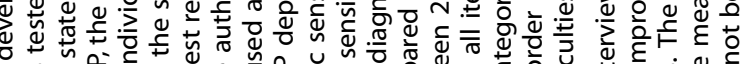
з.

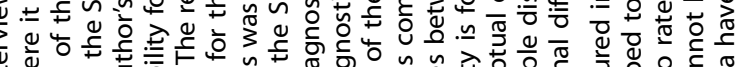

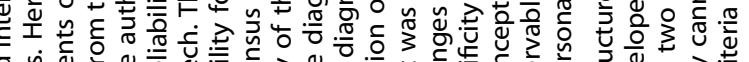

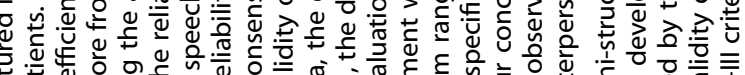

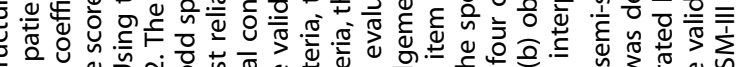

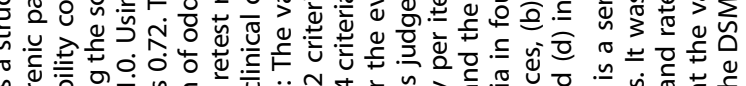

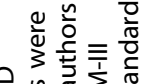

a

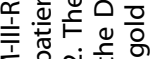

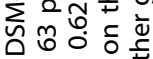

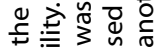

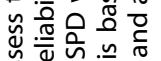

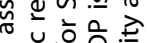

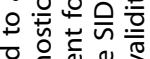

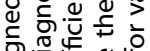

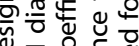

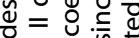
$\because \frac{n}{x} \pi 0$

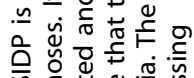

ฮॅ

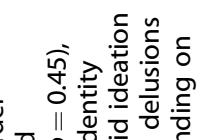

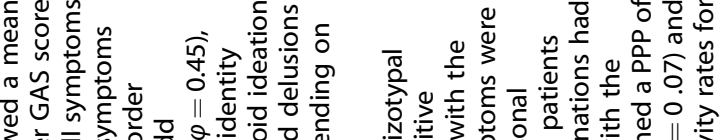

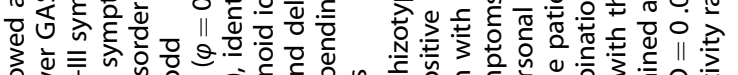

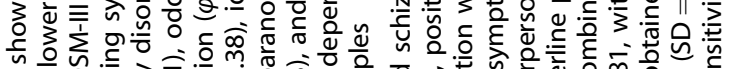

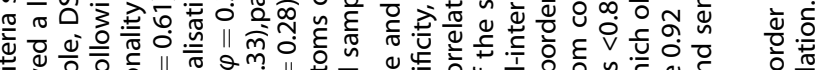

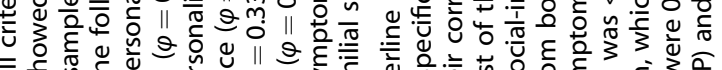

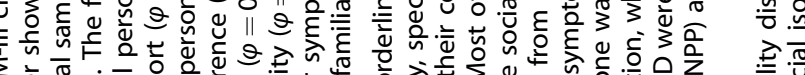

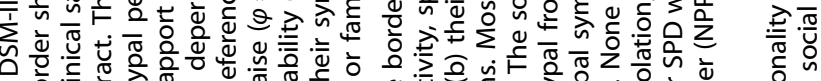

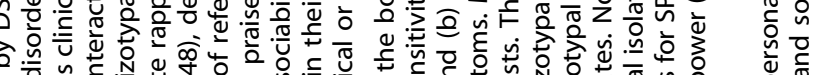

金.

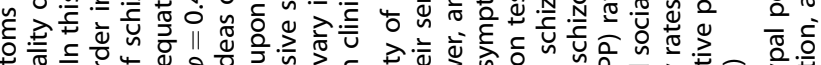

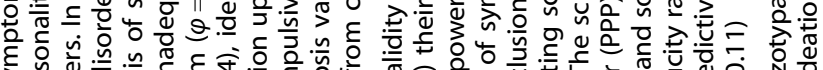

हो人

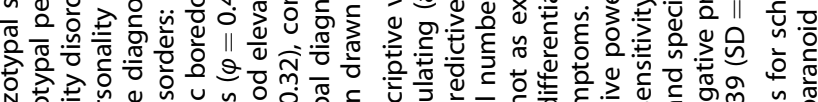

N. 는

น́

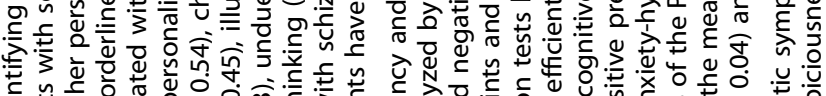

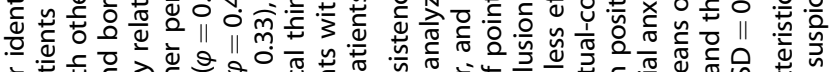

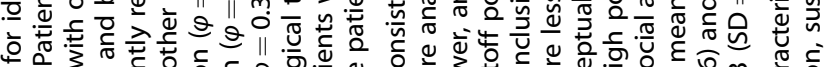

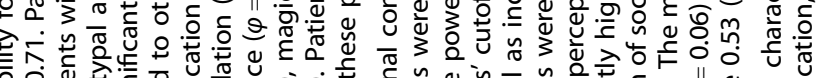

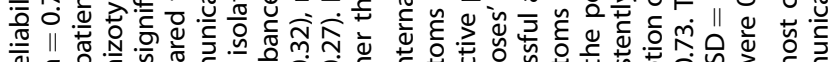

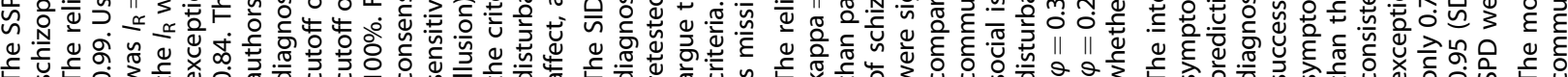
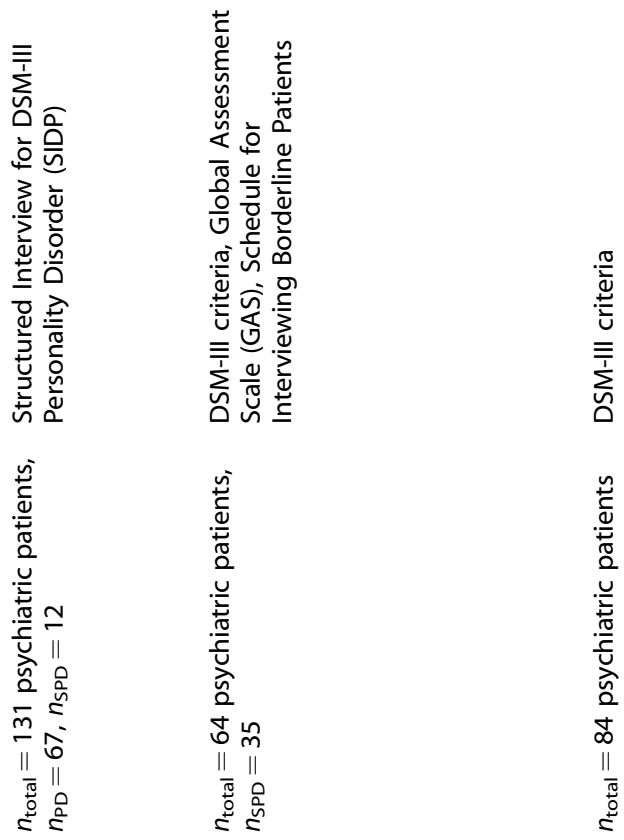

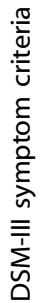

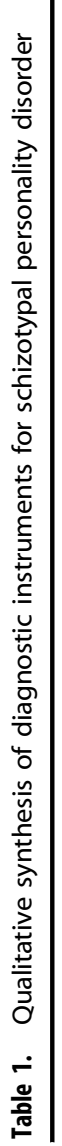

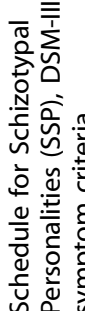

$\underline{\underline{n}}$

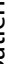

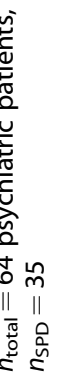

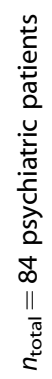

우은

幽

药

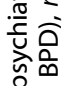

gे 흘

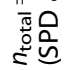

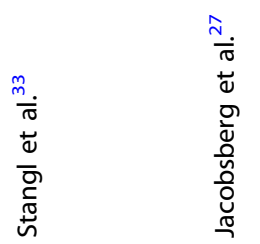

$\frac{\infty}{0}$
$\frac{0}{10}$
$\frac{0}{0}$
$\overline{0}$
$\frac{0}{\overline{0}}$
$\overline{3}$

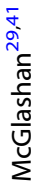




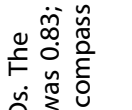

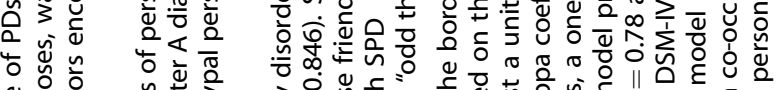

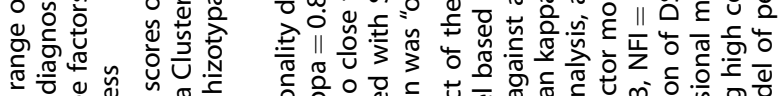

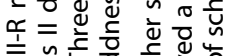

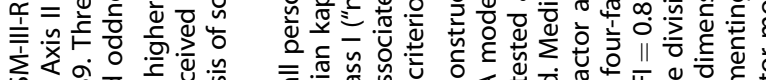

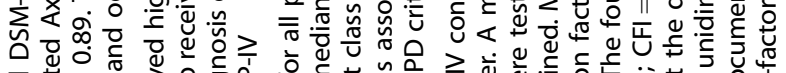

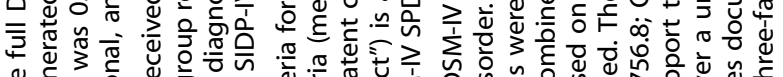

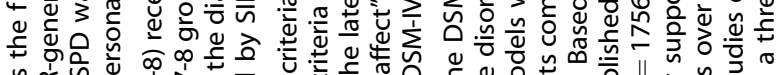

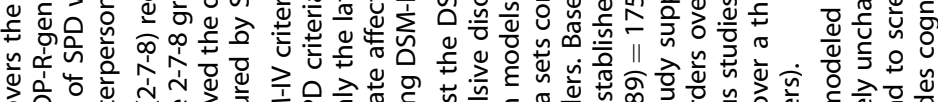

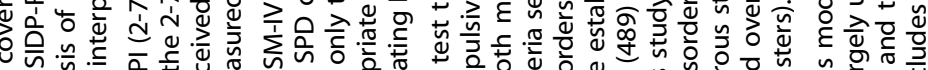

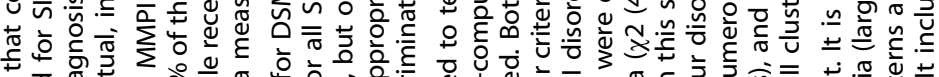

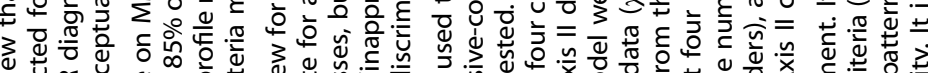

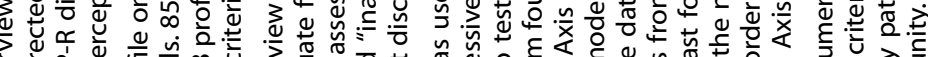

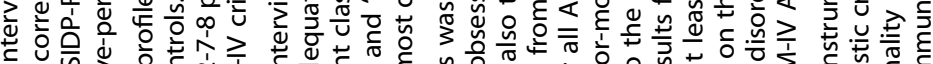

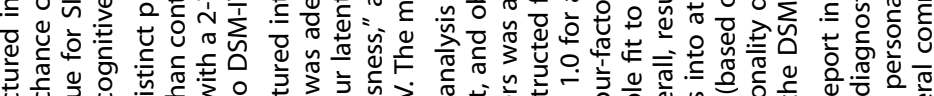

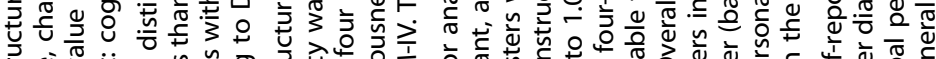

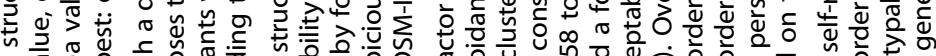

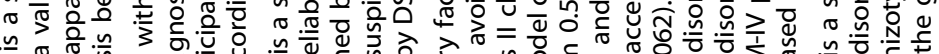

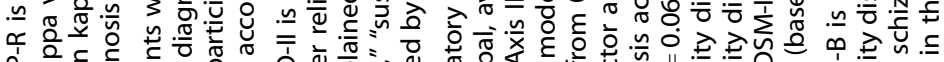

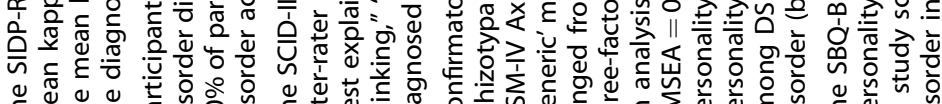

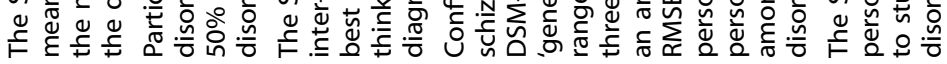
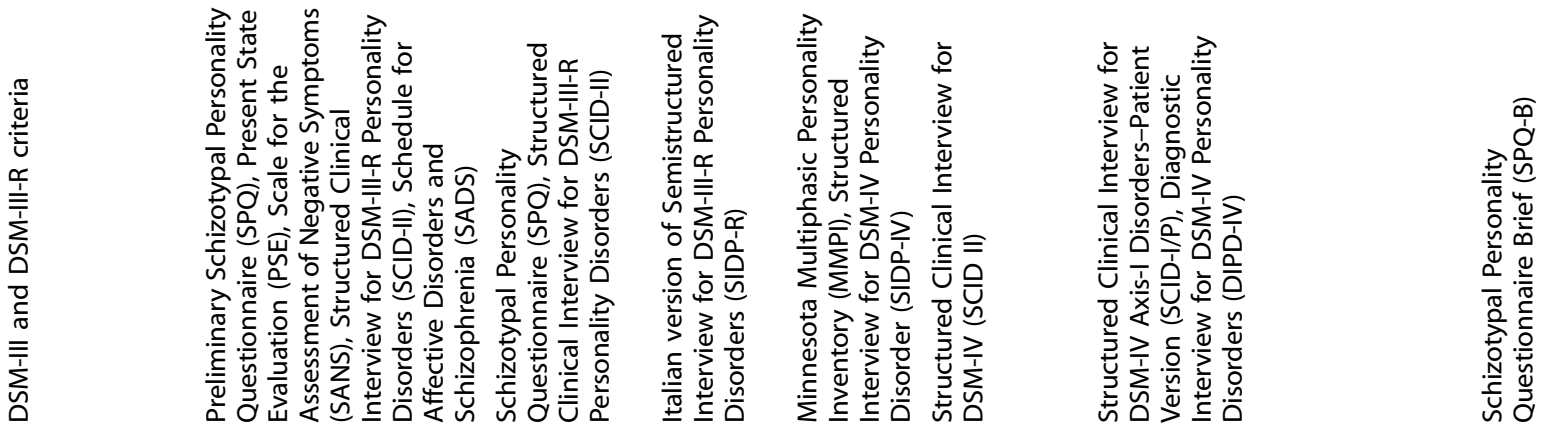

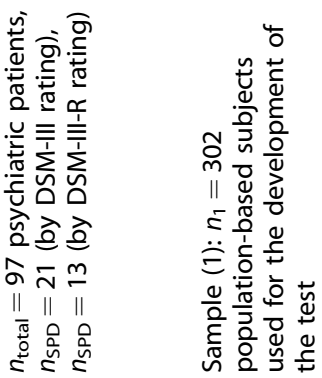
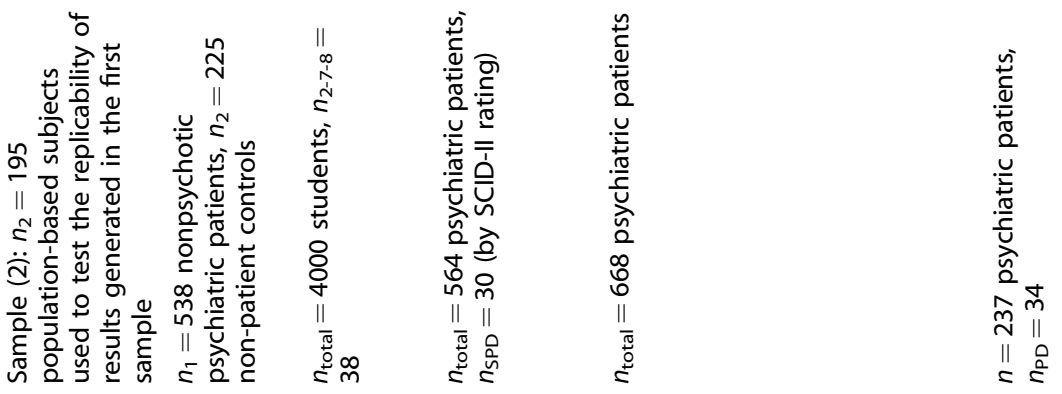
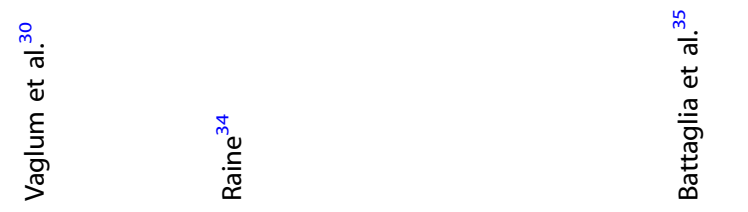

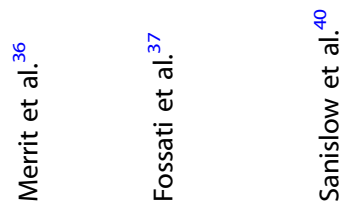

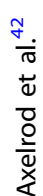




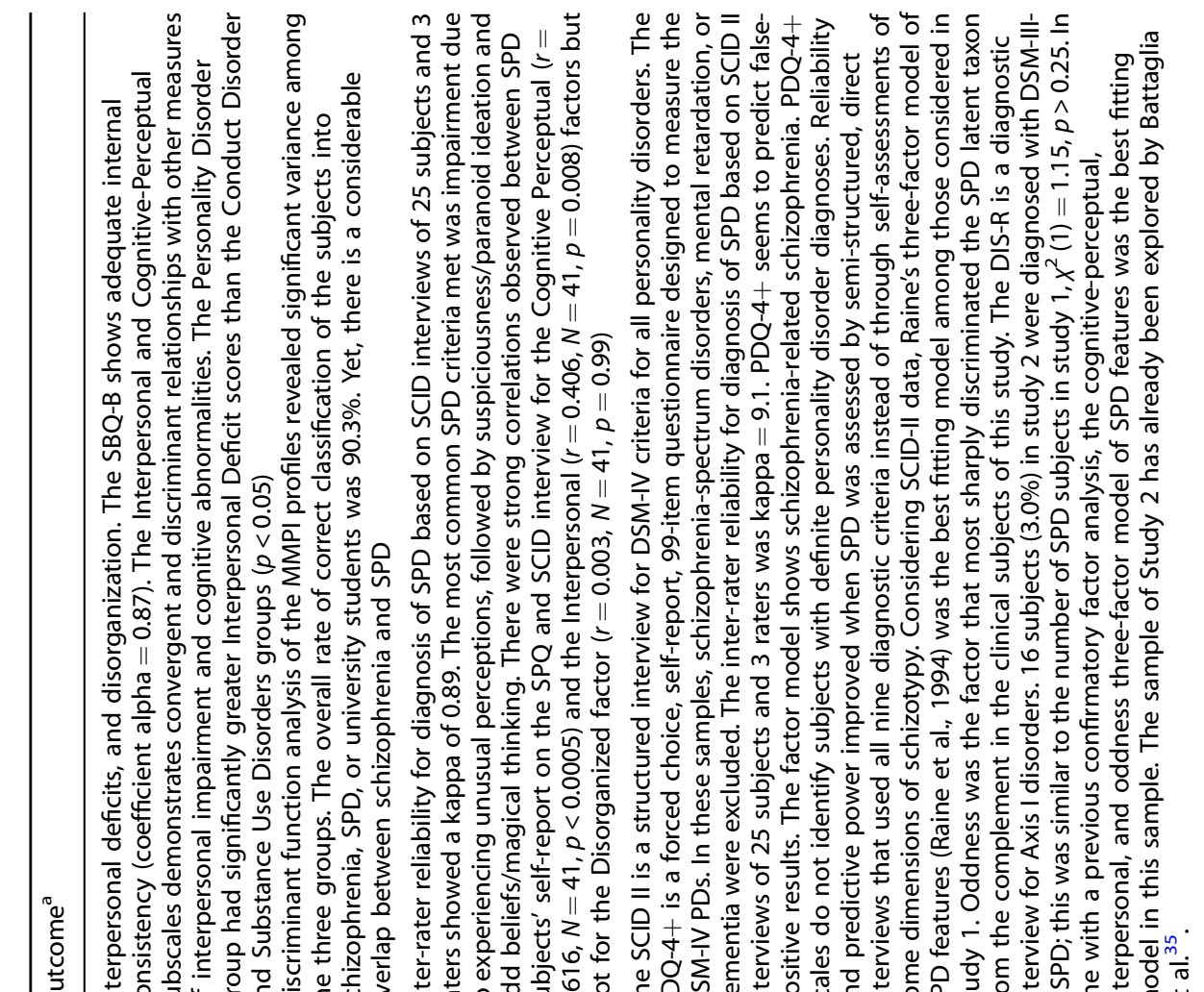

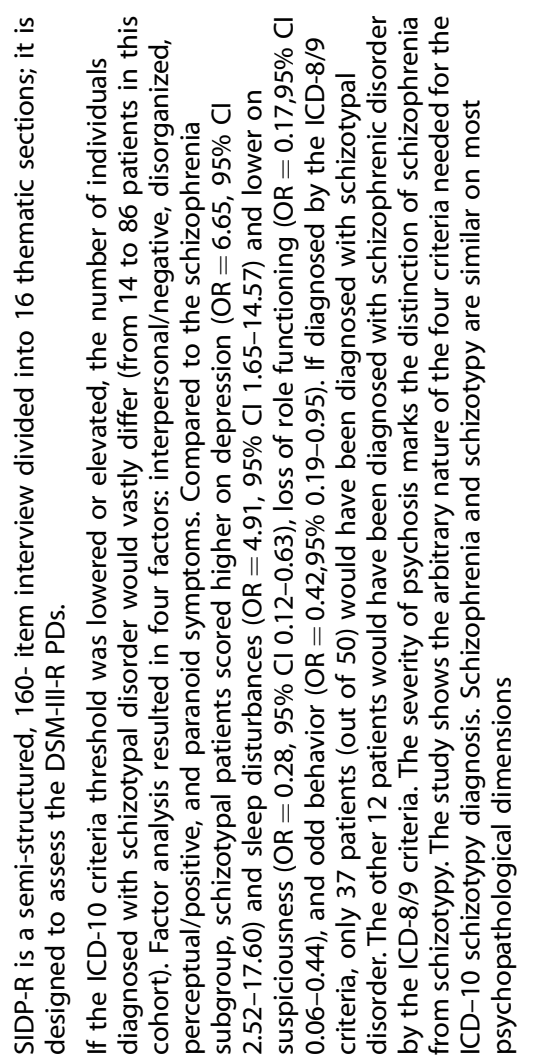

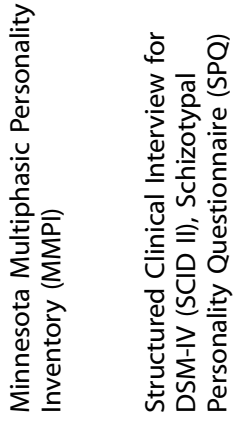

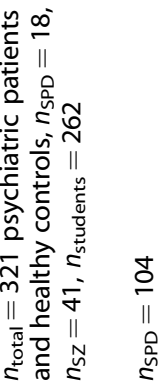

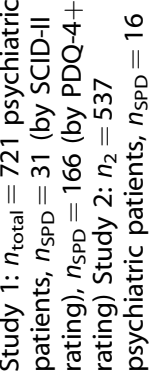

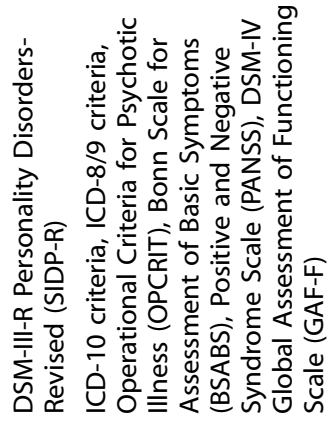

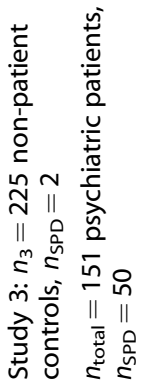


6

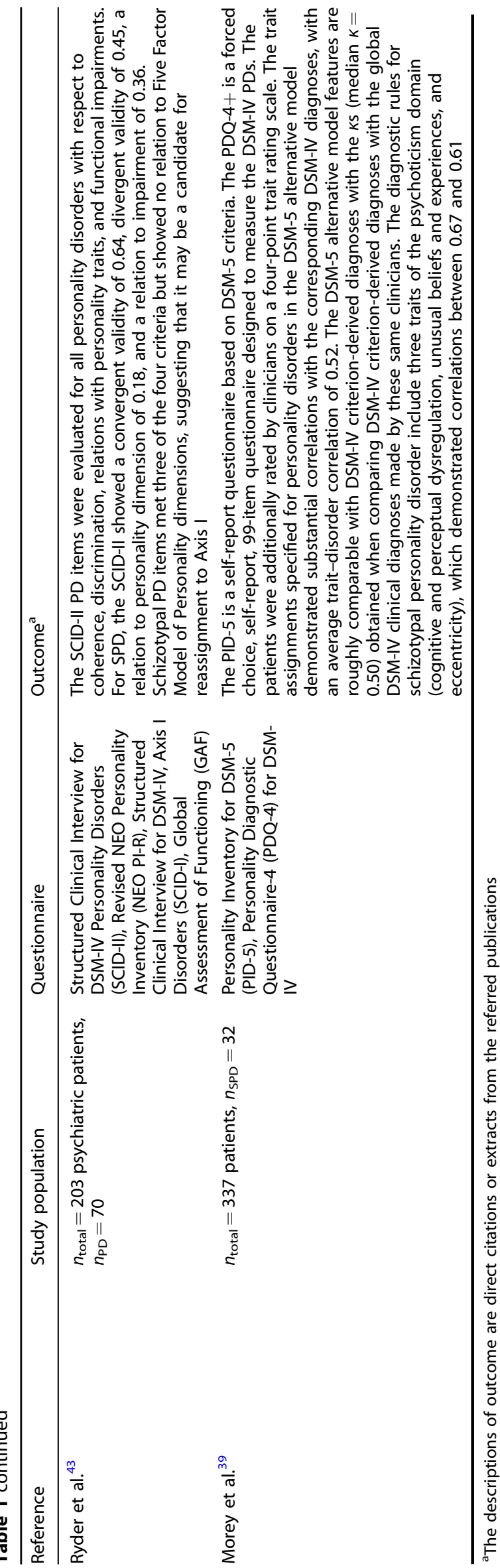

measurements for global functioning, i.e., the Global Assessment of Symptoms ${ }^{60}$ and Clinical Global Impression, ${ }^{50}$ or for depressive symptoms, i.e., the Hamilton Rating Scale for Depression. ${ }^{46,50,62}$ Six studies had cognitive measures, i.e., working memory, ${ }^{49,52,55}$ context processing, ${ }^{51}$ reaction time, ${ }^{54}$ response inhibition, ${ }^{54}$ or a combination of different cognitive categories, ${ }^{53}$ as a primary or secondary outcome.

Individual outcomes. Most of the studies on an antipsychotic drug intervention found a positive effect in STPD (see Table 2A). Thiothixine reduced general symptoms (especially illusions, ideas of reference, paranoid ideation, cognitive deficits, and anxiety) in cohorts of mixed BPD and STPD patients, but the respective studies found no significant relationship between diagnosis and outcome of treatment. ${ }^{47,57}$ Risperidone was the only drug that was evaluated in studies that fulfilled relevant study quality criteria, such as reporting effect sizes, being randomized, and using quantitative measures and standardized questionnaires. It was evaluated in four independent studies: Koenigsberg et al. showed a reduction in the PANSS score in STPD but no difference in the STPD-specific SPQ; ${ }^{50}$ Rabella et al. reported an improvement in reaction time after treatment with risperidone; ${ }^{54}$ McClure et al. found no beneficial effect of risperidone in either the PANSS or cognitive measurements; ${ }^{53}$ and the open-label study by Rybakowski et al. found an increase in social and occupational functioning and cognitive tests after risperidone treatment. ${ }^{62}$ In an open-label augmentation trial, a small cohort $(n=11)$ of patients with STPD had significant improvements in psychosis and depression ratings when treated with olanzapine. ${ }^{60}$ In an openlabel study in patients with comorbid OCD and STPD, a combination of fluvoxamine and olanzapine showed beneficial effects, i.e., it reduced the YBOCS score, ${ }^{59}$ and the concomitant diagnosis of STPD was significantly associated with a positive response. In a retrospective study, Di Lorenzo et al. reported a decrease of general symptoms when patients with schizophrenia spectrum disorder were treated with aripiprazole; patients with STPD were included, but no specific results were mentioned..$^{63}$ In one case report, clozapine treatment reduced symptoms in a patient with comorbid OCD and STPD. ${ }^{66}$ Three studies investigating the use of antipsychotics analyzed mixed cohorts of STPD and BPD patients, ${ }^{47,48,57}$ and one study analyzed patients with schizophrenia spectrum disorder. ${ }^{63}$

Studies evaluating antidepressant treatment examined only mixed (BPD and STPD) or comorbid (OCD and STPD) cohorts (see Table 2B). In an open-label trial of fluoxetine, Markovitz et al. measured a reduction of general symptoms in patients with BPD, STPD, or both, ${ }^{61}$ regardless of the diagnosis. In another study, clomipramine showed no significant effects on OCD symptoms in a cohort of patients with OCD and STPD, and the authors reported a worse treatment outcome in patients with comorbid STPD than in those with other PD diagnoses. ${ }^{46}$ One case report described a patient with STPD who developed psychotic symptoms after treatment with fluoxetine, ${ }^{64}$ and other case reports showed positive effects of clomipramine, paroxetine, and buspirone on depressive or OCD symptoms ${ }^{46,65}$ (see Supplementary Tables $3 C$ and D). Five studies tested other substances and their effect on cognitive impairments in patients with STPD (see Supplementary Table 3): On the basis of studies showing positive results of catecholamine agonistic treatment in schizophrenia-related disorders, Siegel et al. tested d-amphetamine in a cohort of patients with STPD and found an improvement in the Wisconsin Card Sorting Test (WCST); however, the authors found no effect of symptom change on the PANSS score. ${ }^{56}$ Two studies tested dopamine agonists (pergolide and dihydrexidine) and showed improvements in working and verbal memory, executive functioning, information processing, and divided attention. ${ }^{52,55}$ Two studies tested modulators of the autonomous nervous system (intravenous physostigmine, a cholinesterase inhibitor and 
enhancer of the parasympathetic nervous system, and guanfacine, an $a_{2 A}$ receptor agonist and sympatholytic drug) and their effect on cognition. These studies showed improvements in verbal memory, visuospatial working memory, and context processing. ${ }^{49,51}$ The sizes of the studies varied between 1 patient with STPD in a larger mixed cohort ${ }^{63}$ and up to 31 patients with STPD ${ }^{53}$ (see Supplementary Table 2).

\section{Articles on psychotherapy}

Study characteristics. We identified one randomized clinical trial that compared integrated therapy with standard treatment, ${ }^{68}$ one uncontrolled clinical trial, ${ }^{69}$ and one case report of a patient with OCD and comorbid STPD. ${ }^{70}$ The sizes of the studies varied from $1^{70}$ to $79^{68}$ patients with a diagnosis of STPD (see Supplementary Table 2).

Individual outcomes. An uncontrolled prospective trial of a psychodynamic day-care treatment program found no benefit for STPD patients. ${ }^{69}$ One case report showed a reduction of symptoms in a patient with STPD and $\mathrm{OCD}^{70}$ after social skills training. Another trial also reported a positive effect of social skills training, i.e., STPD patients with this training had a lower transition rate from STPD to a psychotic disorder. ${ }^{68}$ We found no trial that evaluated cognitive behavioral therapy in STPD (see Table 3).

\section{Articles on longitudinal course and follow-up studies}

Study characteristics. We included eight studies of clinical cohorts. $^{71-78}$ Studies with mixed clinical and non-clinical cohorts were included if they predicted the development of an STPD diagnosis from childhood to adulthood or the conversion rate to psychotic illness. ${ }^{79-81}$ One article focused of the stability of a diagnosis of STPD in young adult twins. ${ }^{20}$ The study size depended on the investigated cohort (for details see Supplementary Table 2).

Individual outcomes. The follow-up periods of the studies ranged from a minimum of 1 year ${ }^{81}$ to 27 years. ${ }^{80}$ In a mixed cohort of healthy and mentally ill children, Bernstein et al. showed that an early STPD diagnosis during adolescence rarely persisted over a 2year follow-up period. ${ }^{79}$ Along the same lines, in their study in adults Grilo et al. reported a remission of the STPD diagnosis in $61 \%$ of patients and suggested that, although maladaptive traits may persist, the severity of symptoms can change. ${ }^{76}$ In contrast, Asarnow et al. showed that children with a diagnosis of STPD mostly kept the diagnosis, but $25 \%$ of them developed more severe schizophrenia spectrum disorders (schizophrenia or schizoaffective disorder). ${ }^{81}$ Olin et al. evaluated the relationship between personality traits and disorders in a community-based cohort of healthy and mentally ill children and concluded that early traits can be predictive for the development of an STPD. Four studies evaluated longitudinal global functioning and impairment: ${ }^{.74}$ Impairments in global functioning and social impairment differed depending on the study sample, but, overall, patients with pure STPD had less impairment than patients with other comorbid PDs or SZ. In particular, patients with comorbid BPD had poor global functioning. Treatment with antipsychotic medication was common in STPD patients. ${ }^{74,75}$ They were also frequently hospitalized and received psychotherapy. ${ }^{75}$ Two studies evaluated the stability of symptoms over time: McGlashan et al. found paranoid ideation and unusual experiences to be the most stable, whereas oddness appeared to be the least prevalent and most changeable; ${ }^{78}$ and Kendler et al. studied the stability of Cluster A PDs in twins and concluded that genetic risk factors lead to highly stable subtypes of the disorder, whereas shared environmental risk factors lead to rather transient symptoms ${ }^{20}$ (see Table 4). Two studies focused on the conversion from STPD to a psychotic illness and found rates of $25-48 \%$. $^{24,82}$
Quality of the studies

The composition and size of the cohorts varied greatly across the studies, and all treatment studies were single center. Some studies in mixed samples of patients reported results on very few or only single STPD patients. It remains questionable whether the results of these studies can be applied to a larger group of patients with STPD. Most of the articles did not mention disease severity because of a lack of a suitable measurement tool. A variety of methods for evaluating the quality of diagnostic instruments, the outcome of clinical interventional studies (drug treatment or psychotherapy), or longitudinal outcome were applied across the studies, resulting in a high heterogeneity and hampering comparability.

\section{DISCUSSION}

We present a systematic review of diagnostic instruments and pharmacological and psychosocial treatment strategies for STPD. After performing a standardized and systematic literature search and analysis, we assessed 94 full-text articles for eligibility and evaluated 54 of them. At this point, it would be premature to make clear recommendations for the use of specific diagnostic instruments or drug or psychotherapy treatment approaches. Our evaluation of diagnostic instruments made clear that the diagnosis of STPD has changed over time. In each diagnostic system, the threshold for meeting symptom criteria seems to differentiate between related diseases, such as other PDs or schizophrenia. Nearly all the diagnostic instruments discussed for STPD have adequate inter-rater and test-retest reliability. Our review confirms that the SIDP for DSM-III, SIDP-R for DSM-III-R, and SCID-II for DSM-IV are suitable for diagnosing STPD, but we found that the diagnostic tool PDQ-4+ is more suitable for screening. Factor analysis models are frequently discussed as a diagnostic alternative to catalogs with rather arbitrary diagnostic criteria. A complete review of the scales used to access schizotypy as a broad concept can be found in the review by Mason, which focuses not only on the clinical diagnosis but also on psychometric measurements that assess schizotypal personality traits and define a high-risk group for schizophrenia. ${ }^{5}$ Longitudinal studies examined the stability of the diagnostic entity and observed moderate-to-high remission rates between an early childhood onset and later adulthood. Patients suffering of comorbid BPD showed poorer social functioning than patients with pure STPD. ${ }^{71,72}$ Yet, drug treatment responses in patients with comorbid BPD were regardless of the diagnosis. ${ }^{4,57,61}$ Patients suffering of a comorbid OCD showed better response rates after treatment with olanzapine ${ }^{59}$ and poorer responses after clomipramine treatment. ${ }^{46}$ The articles on treatment clearly showed that antipsychotics are the most frequently used drugs. When we considered only studies that were of acceptable methodological quality (see LoEs in Tables 2 and 3 and Supplementary Table 3 and 4), risperidone had the best, but still limited, evidence for reducing clinical symptoms in patients with STPD. Antidepressants have only been tested in mixed cohorts (patients with comorbid OCD or BPD), making it difficult to draw definite conclusions on their effectiveness in STPD. Most of the drug treatment studies were conducted in patients with STPD and a comorbid disorder, which also limits our ability to draw conclusions. Moreover, some studies included only a few patients, resulting in an LoE of $2-$ to 3 . Remarkably, to the best of our knowledge no treatment guidelines or Cochrane Collaboration reviews exist that provide a comprehensive discussion of treatment alternatives for STPD. The WFSBP Guidelines for Biological Treatment of Personality Disorders provide only general recommendations for antipsychotics on the basis of minimal evidence from clinical trials and expert opinion (Herpertz et al. 2007). 


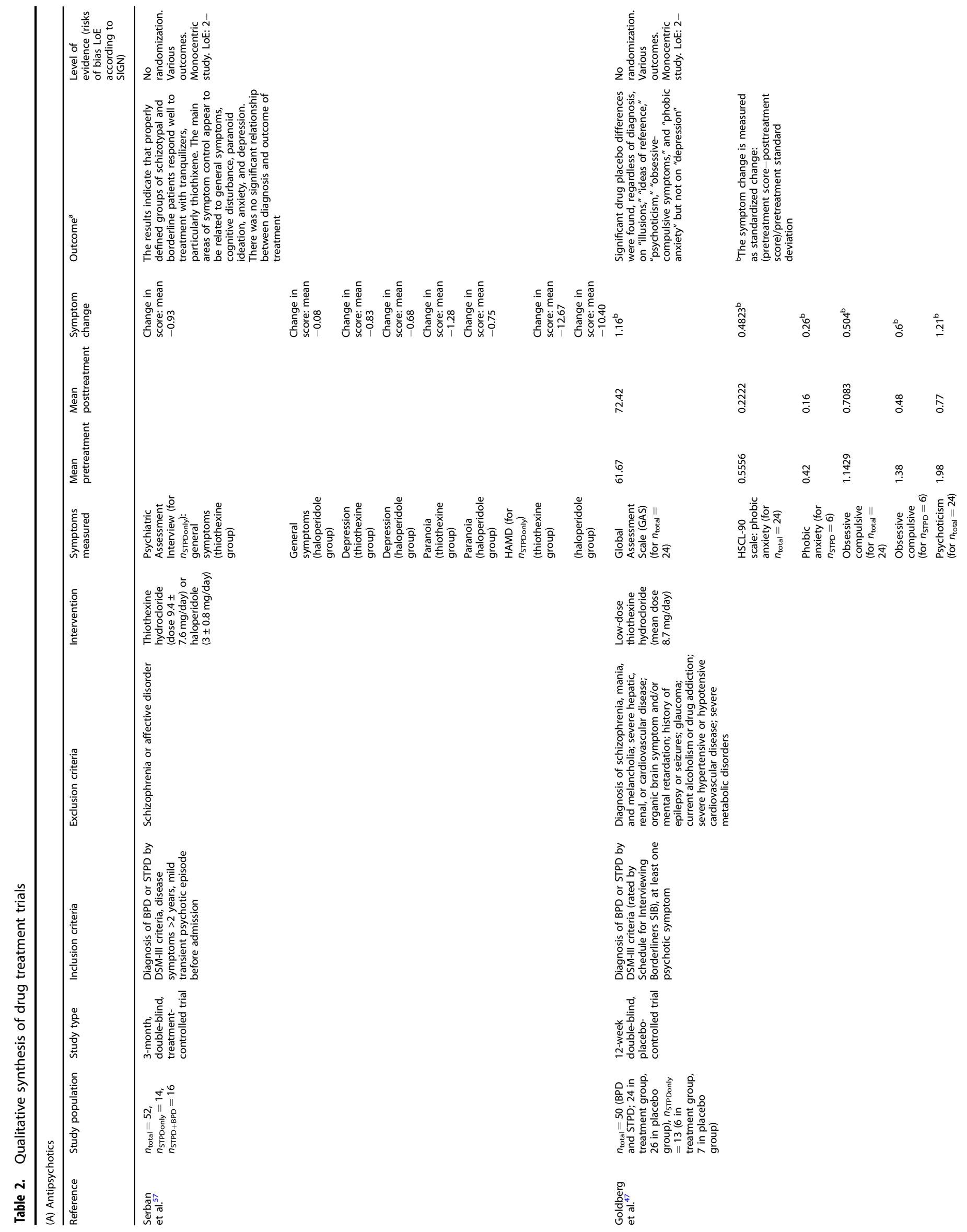




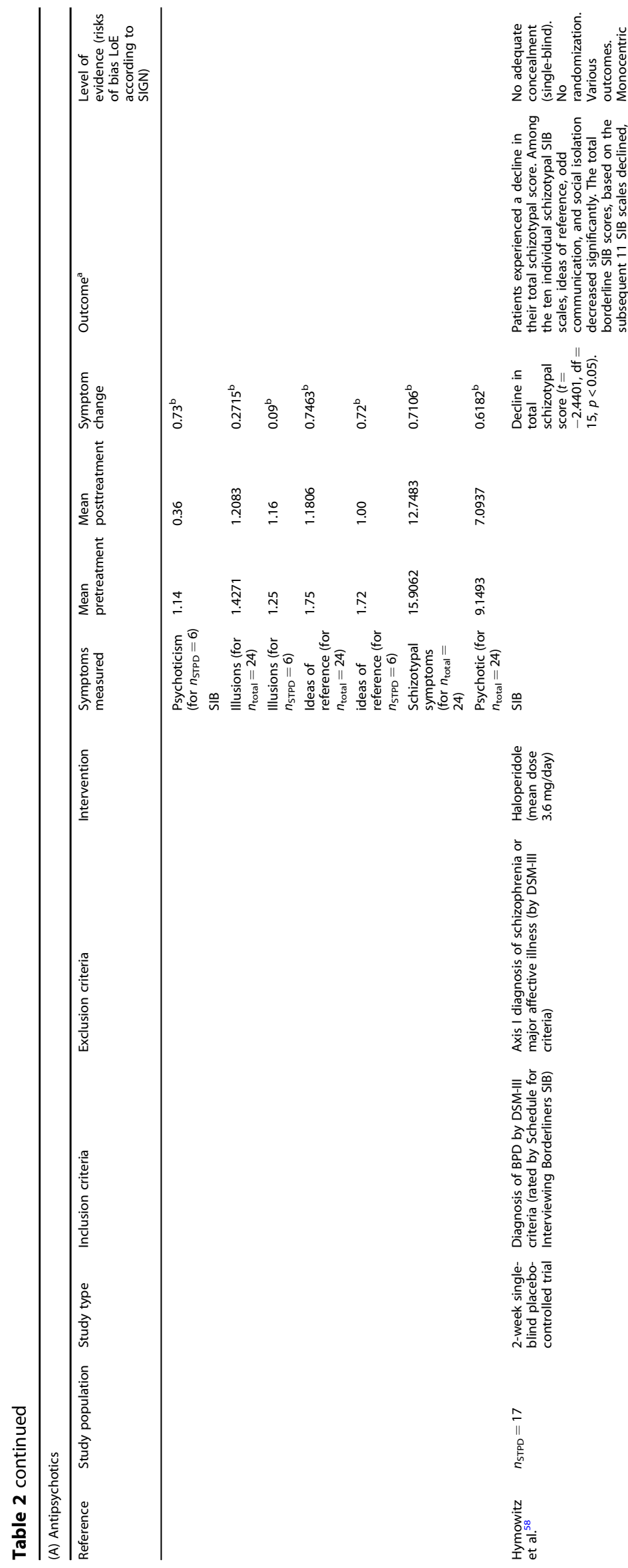

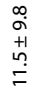

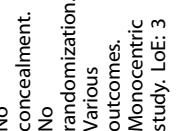

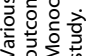

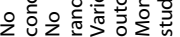

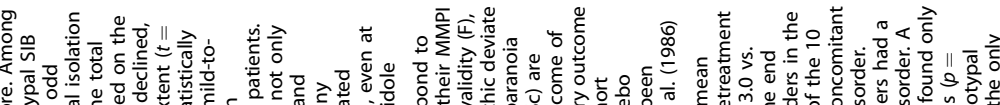

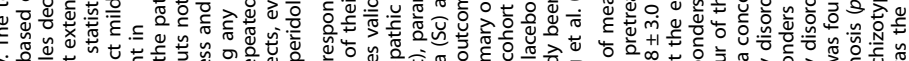

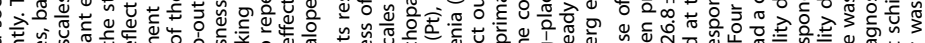

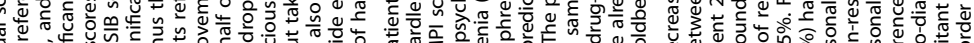

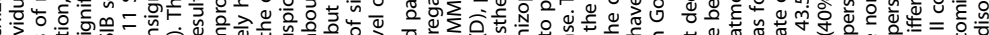

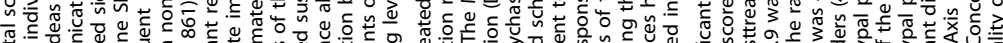

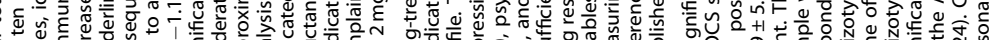

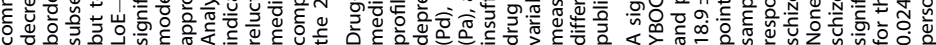

$=\bar{c}$ 


$\mathrm{nPj} \quad$ Diagnosis and treatment of schizotypal personality disorder:...
SK Kirchner et al.

10

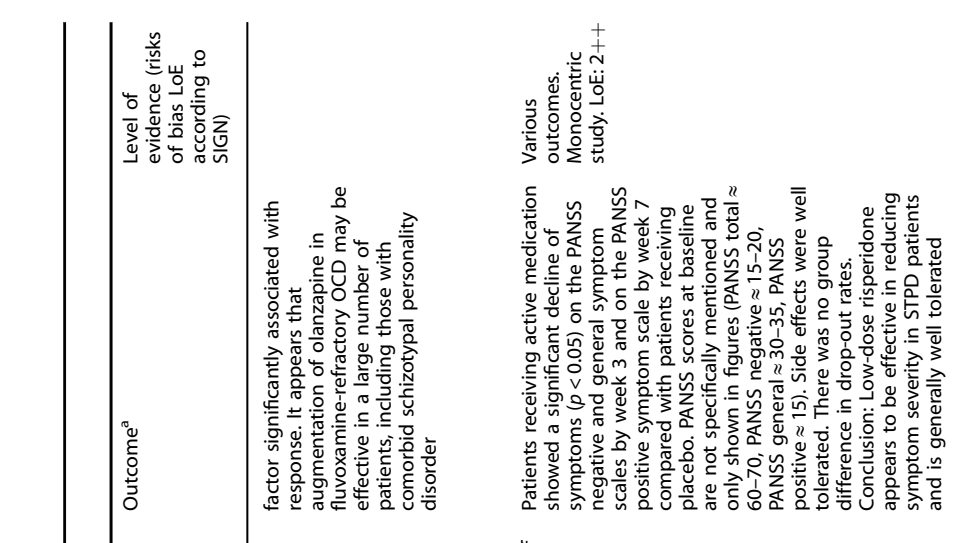

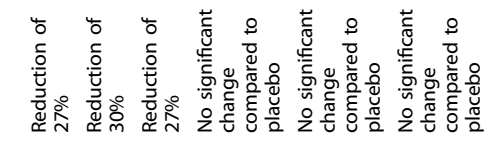

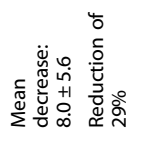

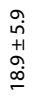

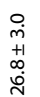

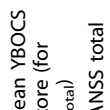

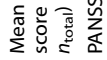
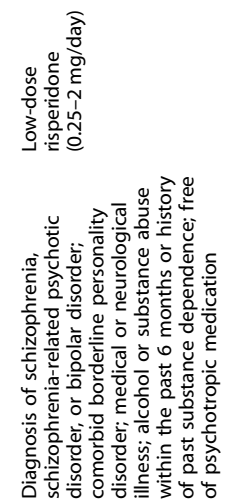

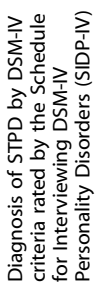

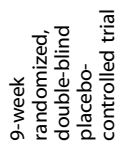

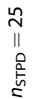

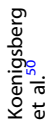

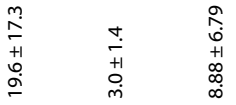

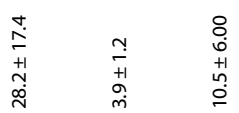

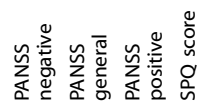

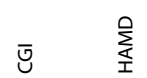

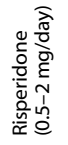

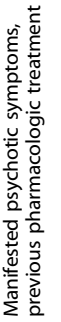

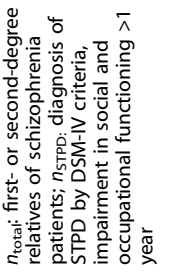

홀

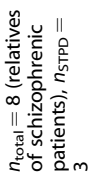

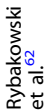




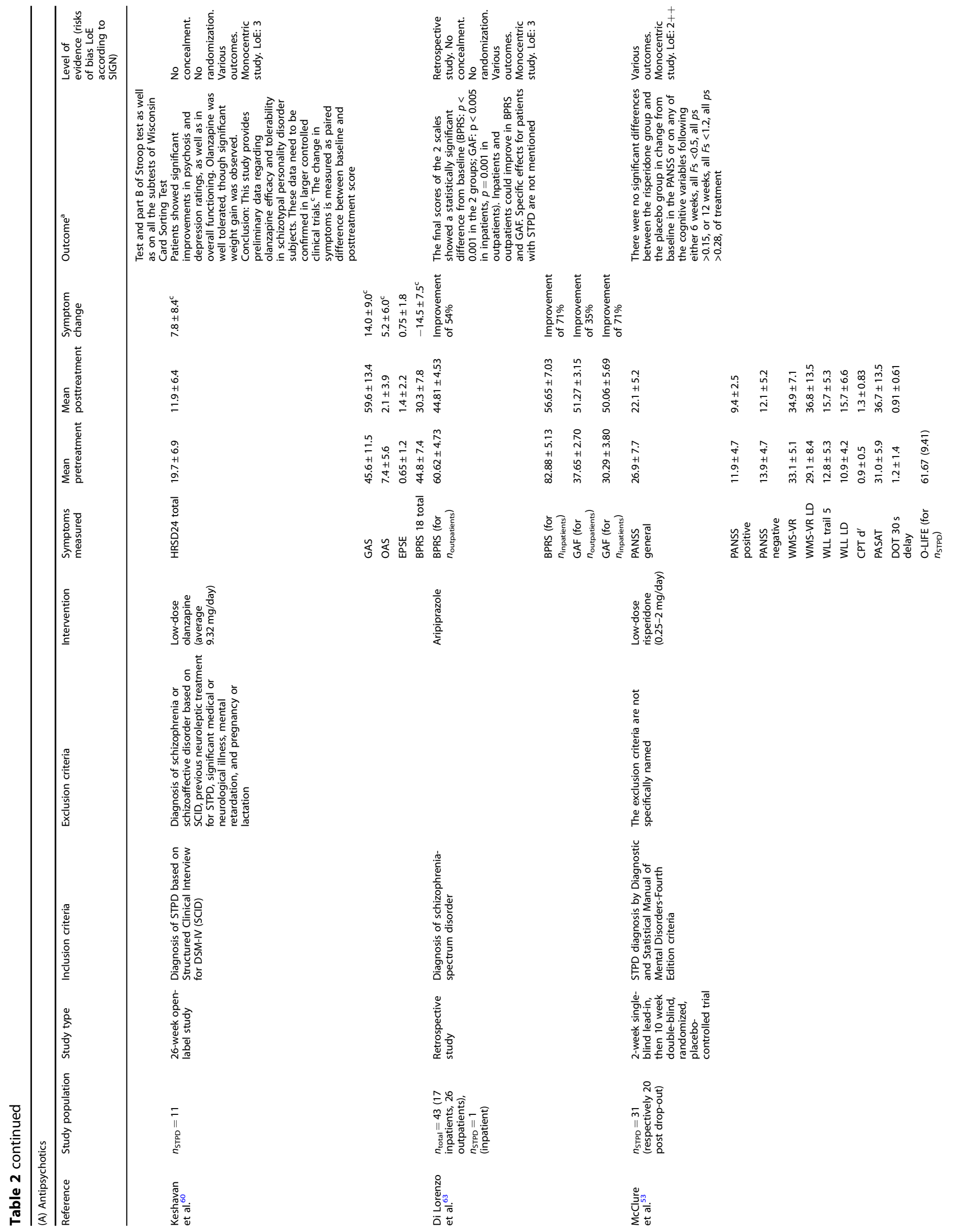




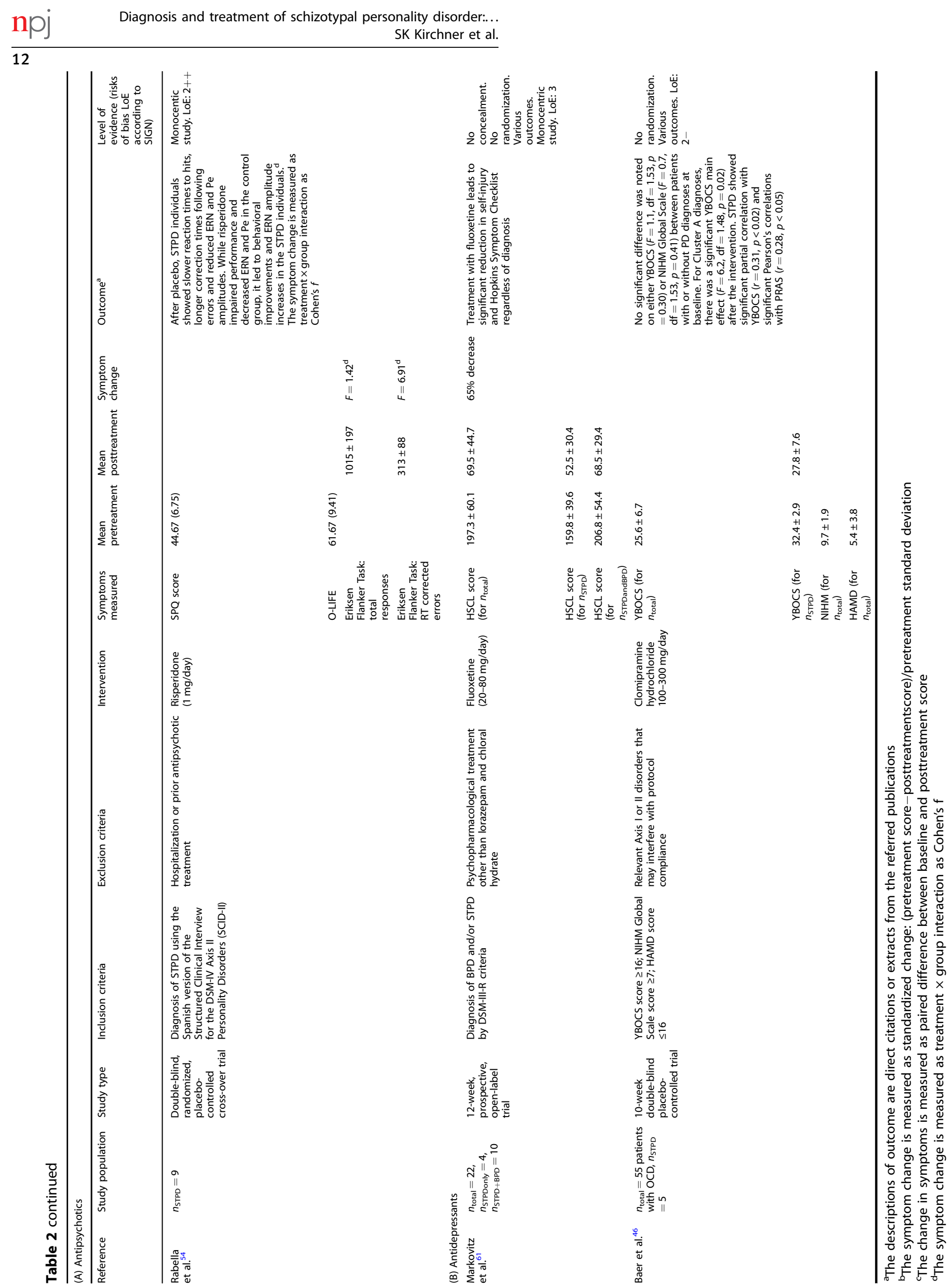


Table 3. Qualitative synthesis of psychotherapy

\begin{tabular}{|c|c|c|c|c|c|c|c|}
\hline Reference & $\begin{array}{l}\text { Study } \\
\text { population }\end{array}$ & Study type & Inclusion criteria & Exclusion criteria & Intervention & Outcome ${ }^{a}$ & $\begin{array}{l}\text { Level of } \\
\text { evidence (risks } \\
\text { of bias LoE } \\
\text { according to } \\
\text { SIGN) }\end{array}$ \\
\hline $\begin{array}{l}\text { Karterud } \\
\text { et al. }\end{array}$ & $\begin{array}{l}n_{\text {total }}=97 \\
n_{\mathrm{PD}}=50 \\
n_{\mathrm{STPD}}=13\end{array}$ & $\begin{array}{l}\text { Non-blinded, } \\
\text { uncontrolled } \\
\text { prospective } \\
\text { trial }\end{array}$ & $\begin{array}{l}\text { Diagnosis of Axis } \\
\text { I or II psychiatric } \\
\text { disorder, for } \\
n_{\text {STPD: diagnosis }} \\
\text { according to } \\
\text { DSM-III-R criteria }\end{array}$ & $\begin{array}{l}\text { Acute psychosis, } \\
\text { intense psychic } \\
\text { suffering with long- } \\
\text { standing incapacity } \\
\text { to function in social } \\
\text { or family roles }\end{array}$ & $\begin{array}{l}\text { 6-month psychodynamic } \\
\text { day treatment including } \\
\text { group psychotherapy ( } 3 \times \\
\text { per week), art therapy } \\
\text { groups }(2 \times \text { per week), body } \\
\text { awareness group }(2 \times \text { per } \\
\text { week), individual } \\
\text { psychotherapy ( } 1 \times \text { per } \\
\text { week), occupational therapy } \\
(1 \times \text { per week) }\end{array}$ & $\begin{array}{l}\text { The improvement of } \\
\text { patients was measured by } \\
\text { the change in symptoms } \\
\text { (measured by General } \\
\text { Symptom Index) and the } \\
\text { Global Functioning } \\
\text { (measured by Health } \\
\text { Sickness Rating Scale). } \\
\text { Whereas patients without } \\
\text { personality disorder } \\
\text { (change in GSI: } 0.77 \pm 0.50, \\
\text { change in HSRS: } 8.9 \pm 6.9, p \\
<0.01 \text { ) improved the most, } \\
\text { followed by the BPD and } \\
\text { OCD groups, the } \\
\text { improvement for patients } \\
\text { with STPD was not } \\
\text { statistically significant } \\
\text { (change in GSI: } 0.40 \pm 0.77 \text {, } \\
\text { change in HSRS: } 0.2 \pm 7.1 \text { ). } \\
\text { No patients committed } \\
\text { suicide. One STPD patient } \\
\text { made a suicidal attempt } \\
\text { and was temporarily } \\
\text { transferred to the acute } \\
\text { ward. One STPD patient } \\
\text { was transferred to long- } \\
\text { term psychiatric hospital } \\
\text { treatment }\end{array}$ & $\begin{array}{l}\text { No } \\
\text { concealment. } \\
\text { No } \\
\text { randomization. } \\
\text { Various } \\
\text { outcomes. } \\
\text { Monocentric } \\
\text { study. LoE: } 3\end{array}$ \\
\hline $\begin{array}{l}\text { McKay } \\
\text { et al. }\end{array}$ & $\begin{array}{l}n_{\text {STPD }}=1 \\
\text { with } \\
\text { comorbid } \\
\text { OCD }\end{array}$ & Case report & $\begin{array}{l}\text { Diagnosis of } \\
\text { STPD by DSM-IV } \\
\text { assessed by } \\
\text { SCID-II; diagnosis } \\
\text { of OCD by DSM- } \\
\text { III-R criteria }\end{array}$ & No criteria & $\begin{array}{l}\text { Social skills training plus } \\
\text { exposure with response } \\
\text { prevention (ERP) }\end{array}$ & $\begin{array}{l}\text { The patient showed a } \\
\text { decrease in OCD } \\
\text { symptomatology as } \\
\text { assessed by the YBOCS, as } \\
\text { well as decreases in } \\
\text { depression and anxiety as } \\
\text { assessed by the Hamilton } \\
\text { Rating Scale for Depression } \\
\text { and the Hamilton Rating } \\
\text { Scale for Anxiety. This is } \\
\text { consistent with the } \\
\text { hypothesis that OCD, when } \\
\text { presented with comorbid } \\
\text { schizotypal personality, is } \\
\text { amenable to social skills } \\
\text { interventions. At 6-month } \\
\text { follow-up, the patient } \\
\text { continued to have } \\
\text { considerable symptoms, } \\
\text { although his level of } \\
\text { functioning had improved } \\
\text { and remained at } \\
\text { posttreatment levels }\end{array}$ & $\begin{array}{l}\text { Case report. } \\
\text { LoE: } 3\end{array}$ \\
\hline $\begin{array}{l}\text { Nordentoft } \\
\text { et al. }\end{array}$ & $n_{\mathrm{STPD}}=79$ & $\begin{array}{l}\text { Randomized } \\
\text { clinical trial } \\
\text { comparing } \\
\text { integrated } \\
\text { treatment with } \\
\text { standard } \\
\text { treatment }\end{array}$ & $\begin{array}{l}\text { Diagnosis of } \\
\text { STPD by the } \\
\text { research criteria } \\
\text { by the WHO } \\
1993 \text { (ICD-10) }\end{array}$ & $\begin{array}{l}\text { Overt psychotic } \\
\text { symptoms }\end{array}$ & $\begin{array}{l}\text { Integrative vs. standard } \\
\text { treatment }\end{array}$ & $\begin{array}{l}\text { In the multivariate model, } \\
\text { male gender increased risk } \\
\text { for transition from STPD to } \\
\text { psychotic disorder (relative } \\
\text { risk }=4.47 \text {, (confidence } \\
\text { interval } 1.30-15.33 \text { )), while } \\
\text { integrated treatment } \\
\text { reduced the risk (relative } \\
\text { risk = } 0.36 \text { (confidence } \\
\text { interval } 0.16-0.85 \text { )). } \\
\text { Significantly more patients } \\
\text { in integrated treatment } \\
\text { than in standard treatment } \\
\text { were treated with } \\
\text { antipsychotic medication. } \\
\text { Integrative treatment } \\
\text { included assertive } \\
\text { community treatment, } \\
\text { social skills training, family } \\
\text { involvement, and psycho- } \\
\text { education }\end{array}$ & $\begin{array}{l}\text { No } \\
\text { concealment. } \\
\text { Monocentric } \\
\text { study. LoE: } 2\end{array}$ \\
\hline
\end{tabular}

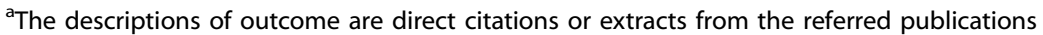


Table 4. Qualitative synthesis of longitudinal outcome studies of patients with schizotypal personality disorder

\begin{tabular}{lll}
\hline Reference & Study population & Follow-up perio \\
\hline Plakun et al. $^{71}$ & $\begin{array}{ll}n_{\text {total }}=237 \text { psychiatric patients, } \\
n_{\text {STPD }}=13, n_{\text {STPD }+ \text { BPD }}=6\end{array}$ & 14 years
\end{tabular}

$\begin{array}{ll}\text { McGlashan }^{72} & n_{\text {total }}=253 \text { psychiatric patients, } \\ & n_{\mathrm{STPD}}=10, n_{\mathrm{STPD}+\mathrm{SZ}}=61, n_{\mathrm{STPD}} \\ & +\mathrm{SZ}+\mathrm{BPD}=30, n_{\mathrm{STPD}+\mathrm{BPD}}=18\end{array}$

Modestin et al. ${ }^{73}$

$n_{\text {total }}=39$ psychiatric patients, $n_{\mathrm{STPD}}=14$ (7 for follow-up), $n_{\mathrm{SZ}}$ $=25$ (17 for follow-up)
Mehlum et al. $^{74}$

$n_{\text {total }}=97$ patients with PD, $n_{\text {STPD }}$ $=13$ at admission, $n_{\text {STPD }}=9$ at discharge

Bernstein et al. ${ }^{79}$ $n_{\text {total }}=733$ community-based adolescents
Range: $2-32$ years

4 years

range: $1.6-4.9$ years

2 years

Range: 15-27 years, based on teachers' school reports

Outcome $^{a}$

Diagnoses in this study were based on DSM-III criteria. Patients suffering from STPD without comorbid major affective disorder functioned better than patients with SZ. They had higher scores in global functioning (GAS) than SZ patients at baseline but not at follow-up. STPD patients with comorbid BPD were as impaired as schizophrenics at admission but significantly better at follow-up

STPD as defined by DSM-III criteria appeared to be common in the Chestnut Lodge follow-up study patients, although it was rare as a pure syndrome. From the perspective of follow-up, STPD seemed to be related to SZ but not to BPD. The mixed Axis II borderline syndrome (STPD+BPD) had a long-term profile closer to BPD than to STPD. The cohorts meeting STPD criteria had relatively poor social adjustments and fewer social contacts. The pure STPD cohort achieved the highest level on education compared to the mixed diagnoses. The pure STPD sample was mainly single (70\%) and male (60\%). Premorbid functioning was poor socially and good instrumentally

Diagnosis of STPD was based on DSM-III, of SZ on ICD-9 and parts on DSM-III. A relationship not only between STPD and SZ but also between STPD and BPD could be detected. Pure STPD patients are rarely dysfunctional and less likely to require hospital care. Therefore, the clinical sample investigated is small and might not be representative for all STPD patients. On a blind examination, STPD patients in this cohort were found to be less socially adjusted and they tended to be more symptomatic. Compared with a small DSM-III schizophrenia subgroup, STPD patients undertook more suicide attempts. STPD patients were rating higher in social dissatisfaction. Patients with STPD were more anxious and they tended to suffer more from obsessive-compulsive symptoms and depression. Transient psychoses were frequent in STPD patients. The average neuroleptics dose was twice as low in STPD compared to SZ ( $92 \%$ of $n_{\text {total }}$ received neuroleptic medication) STPD diagnoses were made according to DSM-III-R at index hospitalization and by SCID interview at follow-up. STPD patients displayed a moderate symptom reduction after 3 years of treatment but retained relatively poor global functioning. They were least socially adjusted, employed, and self-supporting of all diagnostic subgroups. STPD and BPD patients had far more inpatient treatment than other PDs The overall prevalence of personality disorders peaked at age 12 years in boys and at age 13 years in girls and declined thereafter. STPD was the least prevalent Axis II disorder (moderate STPD 1.8\%, severe STPD 1.2\%). Children who met the criteria for STPD had increased social impairments, school or work problems, and a higher comorbidity with Axis I disorders. Longitudinal follow-up revealed that most Axis II disorders did not persist over a 2-year period. Subjects with disorders identified earlier remained at elevated risk for receiving a diagnosis again at follow-up (persistence after 2 years: for moderate STPD 9\%, for severe STPD 11\%)

The lifetime diagnoses used in the study are based on DSM-III-R. The first assessment was at age 15 years, the second at age 25 years, and the third between age 39 and 42 years. Those who later developed STPD were found to be more passive and unengaged and more hypersensitive to criticisms compared with the non-schizophrenia groups according to school reports. Males who developed STPD were found to be less disruptive and hyper-excitable compared with males with schizophrenia; females with STPD did not differ from females with schizophrenia. A receiver operating characteristic analysis found these factors to predict $73.5 \%$ of future STPDs. The three major factors accounting for $54.4 \%$ of the variance were labeled as "socially anxious and withdrawn," "disruptive and hyper-excitable," and "passive and unengaged." These findings suggest that pre-schizotypal traits may be identified in late childhood or adolescence
Comparative groups: $n_{\mathrm{comp} 1}=31$ SZ children, $n_{\text {comp } 2}=37$ nonpsychotic but mentally ill children, $n_{\text {comp3 }}=68$ children not mentally ill but schizophrenic mother, $n_{\text {comp } 4}=60$ healthy children

Grilo et al. $^{76}$ $n_{\text {total }}=633$ patients, $n_{\mathrm{PD}}=544$, $n_{\mathrm{MDD}}=89, n_{\mathrm{STPD}}=78$
2 years
The study examined the stability of different personality disorders over time. The STPD remission rate was $61 \%$ after 24 months. Remission rates after a more stringent definition with two or fewer criteria (by the DSM-IV Personality Disorders Follow Along Version, DIPD-FAV) after 12 consecutive months was $23 \%$ for STPD. Dimensionally, these findings suggest that PDs may be characterized by maladaptive trait constellations that are stable in their structure (individual differences) but can change in severity or expression over time 
Table 4 continued

\begin{tabular}{lll}
\hline Reference & Study population & Follow-up \\
\hline Warner et al. $^{77}$ & $n_{\text {total }}=376$ patients with PD & 2 years
\end{tabular}

Outcome $^{\mathrm{a}}$

Asarnow et al. ${ }^{81} \quad \begin{aligned} & n_{\mathrm{STPD}}=12 \text { children, } n_{\mathrm{SZ}}=18 \quad \text { range: } 1-7 \text { years } \\ & \text { children }\end{aligned}$

\footnotetext{
McGlashan et al. ${ }^{78} \quad n_{\text {total }}=474$ patients with personality disorders, $n_{\mathrm{STPD}}=85$
}

2 years

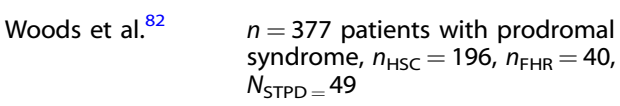

Debbane et al. $^{24}$

$n=376$ patients by a clinically relevant expression of schizotypy (i.e., STPD, schizoid PD, or SD

Kendler et al. ${ }^{20}$

\section{5 years}

range: $2-20$ years

range: 6-11 years
This study explores the extent to which relevant personality traits are stable in individuals diagnosed with four personality disorders (schizotypal, borderline, avoidant, and obsessive-compulsive personality disorders). The PDQ-IV was used for screening. The DIPD-IV was used for making the initial diagnosis based on DSM-IV criteria. The test-retest kappa for STPD was 0.64 . There was an insufficient sample size in the inter-rater reliability sample to calculate the kappa for STPD, but diagnostic agreement was $100 \%$. Participants were interviewed at 6 months, 1 year, and 2 years following the baseline assessment. Changes in personality traits were determined via a re-administration of the NEO-PI-R at the 1- and 2-year follow-up. The DIPD-IV was modified to record the presence of each criterion for the four PDs for each month of the follow-up interval. The standardized parameter estimates reflecting the stability for the latent trait variable across time were significant and quite large $(\beta=0.76$ and $\beta=0.83$, both $p s<0.01)$ as were the stability estimates for STPD $(\beta=0.90$ and $\beta=0.81$, both $p$ s $<0.01)$. The results demonstrate significant cross-lagged relationships between trait change and later disorder change for three of the four personality disorders studied

There was significant continuity between SZ spectrum disorders in childhood and adolescence. The most common clinical outcome for children with STPD was continuing STPD, supporting the hypothesis of continuity between childhood and later STPD. However, $25 \%$ of the STPD sample developed more severe SZ spectrum disorders (schizophrenia or schizoaffective disorder, also supporting the hypothesis that STPD represents a risk or precursor state for more severe SZ spectrum disorders

In this study, a 24-month follow-up was obtained to evaluate the change of personality disorder criteria over time. For STPD, the most prevalent and least changeable criteria over 2 years were paranoid ideation, and unusual experiences. The least prevalent and most changeable criteria were odd behavior and constricted affect

$40 \%$ of prodromal patients converted to fully psychotic illness during 2.5 years of follow-up. Corresponding rates for help-seeking comparison (HSC) group, familial high-risk (FHR) group, and STPD subjects were correspondingly 4,0 , and $36 \%$. Cox regression comparing distinguished prodromal patients from HSC but not from STPD subjects

The conversion rates from STPD to a psychotic disorder varied between $25 \%$ and $48 \%$. Suspected STPD in children, however, seldom led to the later emergence of a schizophrenic-spectrum psychotic disorder (only $6.25 \%$ )

The study examines the stability of genetic and environmental factors in paranoid and schizotypal PD. The stability over time of the criteria counts for STPD, estimated as polychoric correlations, was $+0.40 .71 \%$ of the temporal stability derived from the effect of genetic factors. Shared genetic risk factors for two of the Cluster A PDs are highly stable in adults over a 10-year period while environmental risk factors are relatively transient. Over two thirds of the long-term stability of the common Cluster A PD liability can be attributed to genetic influences

${ }^{\text {a }}$ The descriptions of outcome are direct citations or extracts from the referred publications

In summary, our systematic review shows that the best evidence for efficacy in STPD is available for risperidone and to a limited extent for olanzapine. The literature on psychotherapy is sparse and does not allow us to make any recommendations, although social skills training seems to be effective and should be offered to patients with STPD. Large-scale naturalistic and interventional trials with defined diagnostic cohorts and strict study designs are needed to provide the data for more detailed evidence-based recommendations.

\section{METHODS}

Study selection

This systematic review was conducted by searching the PubMed/ MEDLINE databases for papers published at any time. We conducted the final search on September 14, 2016, at which time the data source contained studies from April 1, 1947, to August 21, 2016. A total of 145 combinations of search terms were used to search the databases with the ENDNOTE X7 search tools (see Supplementary Information). Duplicates were removed by using the ENDNOTE X7 duplication detection feature. The publications (titles and abstracts) were then screened for relevance. To be included, the articles had to report on studies of original data and focus on the diagnosis, treatment, or follow-up of patients with STPD. Because including only studies with a Scottish Intercollegiate Guidelines Network (SIGN) LoE of $1-$ to $1++$ would have limited the number of studies available for inclusion, we included not only randomized control trials but also cohort studies, retrospective non-analytical studies, and case studies (LoE $2++$ to 3). Expert opinions (LoE 4) were not considered. Study designs and LoE grading are described in the Tables $2 \mathrm{~A}, \mathrm{~B}$, and 3, and Supplementary Tables 3 and 4. Reviews, meta-analyses, and nonEnglish publications were excluded. Two reviewers independently analyzed the full-text publications and retrieved data on clinical diagnosis and treatment. We searched also three additional databases (WHO Clinical Trials (http://apps.who.int/trialsearch/), ClinicalTrials (https://clinicaltrials.gov/), and the Cochrane Library (http://www.cochranelibrary.com/)) for ongoing or planned clinical trials and for systematic reviews or meta-analyses. Using the search term "schizotypal personality disorder," we identified 18 
clinical trials. Furthermore, we found two additional trials that had been completed; however, upon closer inspection it became clear that they did not meet the inclusion criteria for this systematic review. We identified one protocol ${ }^{83}$ in the Cochrane Library, but it was withdrawn with no results in 2014.

Our search strategy yielded 3420 unique studies, 3326 of which were excluded after we had screened the titles, abstracts, and article format reviews, resulting in 94 full-text articles. These 94 articles were scanned for the inclusion criteria of this systematic review-to be included, studies had to investigate diagnostic instruments for or the treatment or longitudinal course of STPD. After full-text screening, 38 articles had to be excluded because they did not include original data or were not about clinical patients with STPD. The remaining 56 articles were sorted into the following categories: clinical diagnostic instruments (18 studies), pharmacological treatment (22 studies), psychotherapy (3 studies), and longitudinal course and follow-up (13 studies) (see Supplementary Information). Publications on diagnostic questionnaires were only included if they evaluated diagnostic criteria or questionnaires as assessment tools. Articles on factor analysis models alone were excluded, and publications on drug treatment were excluded if there was no report of a clinical outcome. We identified three overlapping patient cohorts: one in the articles on diagnostic instruments (Battaglia et al. ${ }^{35}$ and Fossati et al. ${ }^{44}$ ); one in the articles on drug treatment (Goldberg et al. $1986^{47}$ and $1987^{48}$ ); and one in the Chestnut Lodge cohort (McGlashan et al. published an article on testing DSM-III criteria ${ }^{29}$ and a 2 -year follow-up study in a separate article ${ }^{72}$ ).

\section{General study characteristics}

We assumed a large heterogeneity in disease severity among the included patients who were recruited in outpatient and inpatient settings. Because of the inconsistent outcome measures in the interventional groups, in our view the available data were not suited to perform quantitative analyses, e.g., with a metaanalytical approach. Some study populations included also healthy and population-based individuals, but these studies were only taken into consideration when a clinical diagnosis of STPD was mentioned. ${ }^{20,34,36,38,79,80}$ Most of the studies focused on adults, although three focused on children and the longitudinal course of their diseases. ${ }^{79-81}$ The study sizes varied greatly, as indicated in Supplementary Table 2.

\section{DATA AVAILABILITY}

This is a systematic review. All data generated or analyzed during this study is included in this published article (or Supplementary Information). No other data are available.

\section{ACKNOWLEDGEMENTS}

The authors thank Jacquie Klesing, Board-certified Editor in the Life Sciences (ELS), for editing assistance with the manuscript.

\section{AUTHOR CONTRIBUTIONS}

S.K.K. and A.H. designed the study. S.K.K. searched the literature. S.K.K. and A.R. extracted the data, and A.H. and J.N. reviewed it. All authors wrote and approved the manuscript.

\section{ADDITIONAL INFORMATION}

Supplementary information accompanies the paper on the npj Schizophrenia website (https://doi.org/10.1038/s41537-018-0062-8).

Competing interests: In the past 5 years, A.H. received a paid speakership from Desitin, Otsuka, Janssen-Cilag, and Lundbeck. He was previously member of an advisory boards of Roche, Otsuka, Lundbeck, and Janssen-Cilag. The authors declare no competing interests.
Publisher's note: Springer Nature remains neutral with regard to jurisdictional claims in published maps and institutional affiliations.

\section{REFERENCES}

1. Raine, A. Schizotypal personality: neurodevelopmental and psychosocial trajectories. Annu. Rev. Clin. Psychol. 2, 291-326 (2006).

2. Fonseca-Pedrero, E. et al. The structure of schizotypal personality traits: a crossnational study. Psychol. Med. 48, 451-462 (2018).

3. Kwapil, T. R., Barrantes-Vidal, N. \& Silvia, P. J. The dimensional structure of the Wisconsin Schizotypy Scales: factor identification and construct validity. Schizophr. Bull. 34, 444-457 (2008).

4. Kwapil, T. R., Gross, G. M., Silvia, P. J., Raulin, M. L. \& Barrantes-Vidal, N. Development and psychometric properties of the Multidimensional Schizotypy Scale: a new measure for assessing positive, negative, and disorganized schizotypy. Schizophr. Res. 193, 209-217 (2018).

5. Mason, O. J. The assessment of schizotypy and its clinical relevance. Schizophr. Bull. 41(Suppl 2), S374-S385 (2015).

6. Meehl, P. E. Schizotaxia, schizotypy, schizophrenia. Arch. Gen. Psychiatry 46, 935-944 (1962).

7. Meehl, P. E. Toward an integrated theory of schizotaxia. J. Pers. Disord. 4, 1-99 (1990).

8. Lenzenweger, M. F. Schizotypy, schizotypic psychopathology and schizophrenia. World Psychiatry 17, 25-26 (2018).

9. Chapman, L. J. et al. Impulsive nonconformity as a trait contributing to the prediction of psychotic-like and schizotypal symptoms. J. Nerv. Ment. Dis. 172, 681-691 (1984).

10. Kwapil, T. R. \& Barrantes-Vidal, N. Schizotypy: looking back and moving forward. Schizophr. Bull. 41(Suppl 2), S366-S373 (2015).

11. Ettinger, U., Meyhofer, I., Steffens, M., Wagner, M. \& Koutsouleris, N. Genetics, cognition, and neurobiology of schizotypal personality: a review of the overlap with schizophrenia. Front. Psychiatry 5, 18 (2014).

12. Fonseca-Pedero, E. D. M. Schizotypal traits and psychotic-like experiences during adolescence: an update. Psicothema 29, 5-17 (2017).

13. Fanous, A. H. et al. Significant correlation in linkage signals from genome-wide scans of schizophrenia and schizotypy. Mol. Psychiatry 12, 958-965 (2007).

14. Walter, E. E., Fernandez, F., Snelling, M. \& Barkus, E. Genetic consideration of schizotypal traits: a review. Front. Psychol. 7, 1769 (2016).

15. Gaebel, W., Zielasek, J. \& Cleveland, H. R. Classifying psychosis--challenges and opportunities. Int. Rev. Psychiatry 24, 538-548 (2012).

16. World Health Organization. The ICD-10 classification of mental and behavioural disorders: clinical descriptions and diagnostic guidelines (World Health Organization, 2016) http://www.who.int/classifications/icd/en/bluebook.pdf.

17. Pulay, A. J. et al. Prevalence, correlates, disability, and comorbidity of DSM-IV schizotypal personality disorder: results from the wave 2 national epidemiologic survey on alcohol and related conditions. Prim. Care. Companion J. Clin. Psychiatry 11, 53-67 (2009).

18. Rosell, D. R., Futterman, S. E., McMaster, A. \& Siever, L. J. Schizotypal personality disorder: a current review. Curr. Psychiatry Rep. 16, 452 (2014).

19. Sobin, C. et al. Evidence of a schizotypy subtype in OCD. J. Psychiatr. Res. 34, 15-24 (2000).

20. Kendler, K. S. et al. A longitudinal twin study of cluster A personality disorders. Psychol. Med. 45, 1531-1538 (2015).

21. Bilder, R. M. et al. Neurocognitive correlates of the COMT Val(158)Met polymorphism in chronic schizophrenia. Biol. Psychiatry 52, 701-707 (2002).

22. Nyegaard, M. et al. CACNA1C (rs1006737) is associated with schizophrenia. Mol. Psychiatry 15, 119-121 (2010).

23. Hodgkinson, C. A. et al. Disrupted in schizophrenia 1 (DISC1): association with schizophrenia, schizoaffective disorder, and bipolar disorder. Am. J. Hum. Genet. 75, 862-872 (2004).

24. Debbane, M. et al. Developing psychosis and its risk states through the lens of schizotypy. Schizophr. Bull. 41(Suppl 2), S396-S407 (2015).

25. Herpertz, S. C. et al. World Federation of Societies of Biological Psychiatry (WFSBP) guidelines for biological treatment of personality disorders. World J. Biol. Psychiatry 8, 212-244 (2007).

26. Moher, D., Liberati, A., Tetzlaff, J., Altman, D. G. \& Group, P. Preferred reporting items for systematic reviews and meta-analyses: the PRISMA statement. Ann. Intern. Med. 151, 264-269 (2009). W264.

27. Jacobsberg, L. B., Hymowitz, P., Barasch, A. \& Frances, A. J. Symptoms of schizotypal personality disorder. Am. J. Psychiatry 143, 1222-1227 (1986).

28. Widiger, T. A., Frances, A., Warner, L. \& Bluhm, C. Diagnostic criteria for the borderline and schizotypal personality disorders. J. Abnorm. Psychol. 95, 43-51 (1986).

29. McGlashan, T. H. Testing DSM-III symptom criteria for schizotypal and borderline personality disorders. Arch. Gen. Psychiatry 44, 143-148 (1987). 
30. Vaglum, P., Friis, S., Vaglum, S. \& Larsen, F. Comparison between personality disorder diagnoses in DSM-III and DSM-III-R: reliability, diagnostic overlap, predictive validity. Psychopathology 22, 309-314 (1989).

31. Handest, P. \& Parnas, J. Clinical characteristics of first-admitted patients with ICD10 schizotypal disorder. Br. J. Psychiatry Suppl. 48, s49-s54 (2005).

32. Perry, J. C., O'Connell, M. E. \& Drake, R. An assessment of the schedule for schizotypal personalities and the DSM-III criteria for diagnosing schizotypal personality disorder. J. Nerv. Ment. Dis. 172, 674-680 (1984).

33. Stangl, D., Pfohl, B., Zimmerman, M., Bowers, W. \& Corenthal, C. A structured interview for the DSM-III personality disorders. A preliminary report. Arch. Gen. Psychiatry 42, 591-596 (1985).

34. Raine, A. The SPQ: a scale for the assessment of schizotypal personality based on DSM-III-R criteria. Schizophr. Bull. 17, 555-564 (1991).

35. Battaglia, M., Cavallini, M. C., Macciardi, F. \& Bellodi, L. The structure of DSM-III-R schizotypal personality disorder diagnosed by direct interviews. Schizophr. Bull. 23, 83-92 (1997).

36. Merritt, R. D., Balogh, D. W. \& Kok, C. J. DSM-IV Cluster A personality disorder diagnoses among young adults with a 2-7-8 MMPI profile. Assessment 5, 273-285 (1998).

37. Fossati, A. et al. Latent class analysis of DSM-IV schizotypal personality disorder criteria in psychiatric patients. Schizophr. Bull. 27, 59-71 (2001).

38. Dickey, C. C. et al. Clinical, cognitive, and social characteristics of a sample of neuroleptic-naive persons with schizotypal personality disorder. Schizophr. Res. 78, 297-308 (2005)

39. Morey, L. C., Benson, K. T. \& Skodol, A. E. Relating DSM-5 section III personality traits to section II personality disorder diagnoses. Psychol. Med. 46, 647-655 (2016).

40. Sanislow, C. A. et al. Confirmatory factor analysis of DSM-IV borderline, schizotypal, avoidant and obsessive-compulsive personality disorders: findings from the Collaborative Longitudinal Personality Disorders Study. Acta Psychiatr. Scand. 105, 28-36 (2002).

41. McGlashan, T. H. Recovery style from mental illness and long-term outcome. J. Nerv. Ment. Dis. 175, 681-685 (1987)

42. Axelrod, S. R., Grilo, C. M., Sanislow, C. \& McGlashan, T. H. Schizotypal Personality Questionnaire-Brief: factor structure and convergent validity in inpatient adolescents. J. Pers. Disord. 15, 168-179 (2001).

43. Ryder, A. G., Costa, P. T. \& Bagby, R. M. Evaluation of the SCID-II personality disorder traits for DSM-IV: coherence, discrimination, relations with general personality traits, and functional impairment. J. Pers. Disord. 21, 626-637 (2007).

44. Fossati, A. et al. Taxonic structure of schizotypal personality disorder: a multipleinstrument, multi-sample study based on mixture models. Psychiatry Res. 137, 71-85 (2005)

45. Matsui, M., Sumiyoshi, T., Niu, L., Kurokawa, K. \& Kurachi, M. Minnesota Multiphasic Personality Inventory profile characteristics of schizotypal personality disorder. Psychiatry Clin. Neurosci. 56, 443-452 (2002).

46. Baer, L. et al. Effect of axis II diagnoses on treatment outcome with clomipramine in 55 patients with obsessive-compulsive disorder. Arch. Gen. Psychiatry 49, 862-866 (1992)

47. Goldberg, S. C. et al. Borderline and schizotypal personality disorders treated with low-dose thiothixene vs placebo. Arch. Gen. Psychiatry 43, 680-686 (1986).

48. Goldberg, S. C., Schulz, S. C., Resnick, R. J., Hamer, R. M. \& Schulz, P. M. Differential prediction of response to thiothixene and placebo in borderline and schizotypal personality disorders. Psychopharmacol. Bull. 23, 342-346 (1987).

49. Kirrane, R. M., Mitropoulou, V., Nunn, M., Silverman, J. \& Siever, L. J. Physostigmine and cognition in schizotypal personality disorder. Schizophr. Res. 48, 1-5 (2001).

50. Koenigsberg, H. W. et al. Risperidone in the treatment of schizotypal personality disorder. J. Clin. Psychiatry 64, 628-634 (2003).

51. McClure, M. M. et al. The effects of guanfacine on context processing abnormalities in schizotypal personality disorder. Biol. Psychiatry 61, 1157-1160 (2007).

52. McClure, M. M. et al. Pergolide treatment of cognitive deficits associated with schizotypal personality disorder: continued evidence of the importance of the dopamine system in the schizophrenia spectrum. Neuropsychopharmacology $\mathbf{3 5}$ 1356-1362 (2010).

53. McClure, M. M. et al. The effects of risperidone on the cognitive performance of individuals with schizotypal personality disorder. J. Clin. Psychopharmacol. 29, 396-398 (2009)

54. Rabella, M. et al. Neurophysiological evidence of impaired self-monitoring in schizotypal personality disorder and its reversal by dopaminergic antagonism. Neuroimage Clin. 11, 770-779 (2016).

55. Rosell, D. R. et al. Effects of the D1 dopamine receptor agonist dihydrexidine (DAR-0100A) on working memory in schizotypal personality disorder. Neuropsychopharmacology 40, 446-453 (2015).

56. Siegel, B. V. et al. D-amphetamine challenge effects on Wisconsin Card Sort Test Performance in schizotypal personality disorder. Schizophr. Res. 20, 29-32 (1996).
57. Serban, G. \& Siegel, S. Response of borderline and schizotypal patients to small doses of thiothixene and haloperidol. Am. J. Psychiatry 141, 1455-1458 (1984).

58. Hymowitz, P., Frances, A., Jacobsberg, L. B., Sickles, M. \& Hoyt, R. Neuroleptic treatment of schizotypal personality disorders. Compr. Psychiatry 27, 267-271 (1986).

59. Bogetto, F., Bellino, S., Vaschetto, P. \& Ziero, S. Olanzapine augmentation of fluvoxamine-refractory obsessive-compulsive disorder (OCD): a 12-week open trial. Psychiatry Res. 96, 91-98 (2000).

60. Keshavan, M., Shad, M., Soloff, P. \& Schooler, N. Efficacy and tolerability of olanzapine in the treatment of schizotypal personality disorder. Schizophr. Res. 71, 97-101 (2004).

61. Markovitz, P. J., Calabrese, J. R., Schulz, S. C. \& Meltzer, H. Y. Fluoxetine in the treatment of borderline and schizotypal personality disorders. Am. J. Psychiatry 148, 1064-1067 (1991)

62. Rybakowski, J. K., Drozdz, W. \& Borkowska, A. Low dose risperidone in the treatment of schizophrenia-like symptoms in high-risk subjects. J. Clin. Psychopharmacol. 23, 674-675 (2003).

63. Di Lorenzo, R. et al. Aripiprazole: effectiveness and safety under naturalistic conditions. Exp. Clin. Psychopharmacol. 15, 569-575 (2007).

64. Gutkovich, Z., Rosenthal, R. N. \& Bogdonoff, L. Transient psychosis with psychogenic polydipsia in schizotypal patient taking fluoxetine. Psychosomatics 39 295-296 (1998)

65. Heiden, A., de Zwaan, M., Frey, R., Presslich, O. \& Kasper, S. Paroxetine in a patient with obsessive-compulsive disorder, anorexia nervosa and schizotypal personality disorder. J. Psychiatry Neurosci. 23, 179-180 (1998).

66. Poyurovsky, M. Clozapine in treatment-refractory obsessive-compulsive disorder with comorbid schizotypal personality disorder. Isr. J. Psychiatry Relat. Sci. 45, 219-220 (2008)

67. Zwier, K. J. \& Rao, U. Buspirone use in an adolescent with social phobia and mixed personality disorder (cluster A type). J. Am. Acad. Child Adolesc. Psychiatry 33 1007-1011 (1994).

68. Nordentoft, M. et al. Transition rates from schizotypal disorder to psychotic disorder for first-contact patients included in the OPUS trial. A randomized clinical trial of integrated treatment and standard treatment. Schizophr. Res. 83, 29-40 (2006).

69. Karterud, S. et al. Day hospital therapeutic community treatment for patients with personality disorders. An empirical evaluation of the containment function. J. Nerv. Ment. Dis. 180, 238-243 (1992).

70. McKay, D. \& Neziroglu, F. Social skills training in a case of obsessive-compulsive disorder with schizotypal personality disorder. J. Behav. Ther. Exp. Psychiatry 27, 189-194 (1996).

71. Plakun, E. M., Burkhardt, P. E. \& Muller, J. P. 14-year follow-up of borderline and schizotypal personality disorders. Compr. Psychiatry 26, 448-455 (1985).

72. McGlashan, T. H. Schizotypal personality disorder. Chestnut Lodge follow-up study: VI. Long-term follow-up perspectives. Arch. Gen. Psychiatry 43, 329-334 (1986).

73. Modestin, J., Foglia, A. \& Toffler, G. Comparative study of schizotypal and schizophrenic patients. Psychopathology 22, 1-13 (1989).

74. Mehlum, L. et al. Personality disorders 2-5 years after treatment: a prospective follow-up study. Acta Psychiatr. Scand. 84, 72-77 (1991).

75. Bender, D. S. et al. Treatment utilization by patients with personality disorders. Am. J. Psychiatry 158, 295-302 (2001).

76. Grilo, C. M. et al. Two-year stability and change of schizotypal, borderline, avoidant, and obsessive-compulsive personality disorders. J. Consult. Clin. Psychol. 72, 767-775 (2004)

77. Warner, M. B. et al. The longitudinal relationship of personality traits and disorders. J. Abnorm. Psychol. 113, 217-227 (2004).

78. McGlashan, T. H. et al. Two-year prevalence and stability of individual DSM-IV criteria for schizotypal, borderline, avoidant, and obsessive-compulsive personality disorders: toward a hybrid model of axis II disorders. Am. J. Psychiatry 162 883-889 (2005).

79. Bernstein, D. P. et al. Prevalence and stability of the DSM-III-R personality disorders in a community-based survey of adolescents. Am. J. Psychiatry 150 1237-1243 (1993).

80. Olin, S. S. et al. Childhood behavior precursors of schizotypal personality disorder. Schizophr. Bull. 23, 93-103 (1997).

81. Asarnow, J. R. Childhood-onset schizotypal disorder: a follow-up study and comparison with childhood-onset schizophrenia. J. Child Adolesc. Psychopharmacol. 15, 395-402 (2005).

82. Woods, S. W. et al. Validity of the prodromal risk syndrome for first psychosis: findings from the North American Prodrome Longitudinal Study. Schizophr. Bull. 35, 894-908 (2009)

83. Farooq, S., et al. Pharmacological interventions for schizotypal personality disorder. Cochrane Database Syst. Rev. CD009047 (2011). 
article is licensed und Attribution 4.0 International License, which permits use, sharing, adaptation, distribution and reproduction in any medium or format, as long as you give appropriate credit to the original author(s) and the source, provide a link to the Creative Commons license, and indicate if changes were made. The images or other third party material in this article are included in the article's Creative Commons license, unless indicated otherwise in a credit line to the material. If material is not included in the article's Creative Commons license and your intended use is not permitted by statutory regulation or exceeds the permitted use, you will need to obtain permission directly from the copyright holder. To view a copy of this license, visit http://creativecommons. org/licenses/by/4.0/.

(c) The Author(s) 2018 